Aus der chirurgischen Universitätsklinik und Poliklinik (Direktor : Geheimrat Prof. Dr. E. Payr).

\title{
Die Arthritis acromio-clavicularis als wichtiges Glied in der Pathologie der stumpfen Schulterverletzungen.
}

\author{
Zugleich ein Beitrag zur Periarthritis humerosca- \\ pularis und der Bursitis subacromialis.
}

Von Roderich Sievers.

(Mit I2 Abbildungen.)

Unsere Kenntnisse in der Klinik der stumpfen Schulterverletzungen sind noch recht lückenhaft und vielfach unklar. Bei der sehr großen. Zahl dieser Verletzungen, die durch die Poliklinik geht, und ihren sehr unerfreulichen Folgezuständen, denen unsere Therapie nur unvollkommen gewachsen ist, wird ein jeder Versuch, die Lücken zu füllen, seine Berechtigung haben, zumal man sich des Eindruckes nicht erwehren kann, daß das fragliche Gebiet nur manchen ein Sorgenkind, vielen aber ein Stiefkind ist.

Von jeher war man bestrebt, eine scharfe Grenze zu ziehen zwischen artikulären und zirkumartikulären Affektionen, ohne rechte Fortschritte in der diagnostischen Trennung beider zu machen. Einen solchen brachten erst die Arbeiten Jarjaways und Duplays, die auf die Bedeutung der zirkumartikulären Schleimbeutel hinweisen.

Zwischen der durch die muskulösen und sehnigen Ausläufer des Musculus supraspinatus, infraspinatus und teres minor, des Subscapularis und langen Bicepskopfes verstärkten Schultergelenkkapsel und dem vom Akromion, dem Processus coracoideus, dem Ligamentum coracoacromiale und dem Deltamuskel gebildeten Schultergewölbe befindet sich der für die Funktion des Schultergelenks wichtige Spaltraum, das Spatium subdeltoi- 
de u m. Man kann ihn als ein zweites Gelenk ansehen, das dazu dient, die freie Beweglichkeit der verschiedenen Abschnitte des Deltamuskels über seiner Unterlage, die Fältelung der Gelenkkapsel und das Hindurchschlüpfen des Tuberculum maj. humeri unter das Akromion bei Elevationen des Oberarms (Abduktion) zu ermöglichen.

Seine Gleitfähigkeit wird durch zwei größere Schleimbeutel, die Bursa subacromialis und subdeltoidea garantiert. In der eingehenden Monographie Heinekes finden wir ihre Lage folgendermaßen beschrieben: Die Bursa subacromialis liegt zwischen Akromion, dem lateralen Teil des Lig. coracoacromiale und dem akromialen Ursprung des Musc. deltoideus einerseits, der Schultergelenkkapsel andererseits, die Bursa subdeltoidea zwischen dem Musculus deltoideus und dem fibrösen Gewebe, das das Tuberculum majus überzieht. Die Bursa subacromialis ist nach $\mathrm{Heineke}$ der ansehnlichere Beutel, der häufig mit dem anderen in offener Verbindung steht, so daß dieser nur als eine Ausbuchtung jenes imponiert. Wichtig ist auch die zwischen dem Processus coracoideus, den Ansätzen des Biceps und Coracobrachialis und dem lateralen Teil des Subscapularis gelegene Bursa subcoracoidea, die ebenfalls mit den zuerst genannten in Kommunikation stehen kann. $\mathrm{K}$ üster fand in solchen Fällen „einen großen einheitlichen Sack, der sich nach oben bis tief unter das Akromion, nach unten über den größten Teil der vorderen Gelenkkapsel erstreckte, und zwar so, daß er zwischen Deltamuskel und Gelenkkapsel lagerte und sich nach außen bis in die Nähe des Tuberculum majus erstreckte". Jarjaway lenkte die Aufmerksamkeit zuerst auf die Rolle, die die Schleimbeutel in der Pathologie der Schulter spielen, indem er ein Krankheitsbild beschrieb, das er als akute Bursitis auffaßte und das auch spätere Autoren anerkannt haben. Noch größere Bedeutung wird aber den Publikationen Duplays beigemessen, der einen durch chronische, adhäsive Entzündung in den genannten Schleimbeuteln verursachten Symptomenkomplex als Periarthrite scapulohumérale bezeichnete.

Die akute Form tritt meist nach einmaliger ungewohnter Anstrengung der Schulter ein. Küster beschuldigt vor allem ungewöhnliche Anstrengung des Deltamuskels, Zesas spricht 
Die Arthritis acromio-clavicularis als wichtiges Glied in der Pathologie usw. 585

von mehr allgemein brüsken Bewegungen des Armes, sowie be: sonders von Torsion desselben und Quetschungen der Schultergegend als ursächlichem Moment. Sofortiger heftiger Schmerz in der Schulter, der besonders gern auf dem Wege des Nerv, cutaneus brachii medialis nach der Innenseite des Oberarms bis zum Ellenbogen ausstrahlt, und das Gefühl der Ermüdung. und Kraftlosigkeit sind die Folge, wozu sich eine Bewegungsbeschränkung gesellt, die vorwiegend die Abduktion betrifft. Man findet unter dem Akromion eine nicht scharf abgrenzbare druckschmerzhafte Schwellung, die nach $\mathrm{K}$ üs ter besonders beim Blick von hinten oben als rundliche Erhebung sichtbar sein soll. Bei passiven Rotationen des Humerus soll weiches Reiben zu bemerken sein, das durch Fibrinniederschläge an den Wänden der erkrankten Bursa hervorgerufen wird.

Die akute Entzündung heilt manchmal nach mehreren 'Tagen ohne Folgen aus, geht aber nicht selten in das chronische Stadium über. Die chronische Bursitis soll aber auch als selbständiges Leiden auftreten, oder sich an schwere Schulterkontusionen, Luxationen und Frakturen am oberen Humerusende, besonders an langdauernde Fixation der Schulter wegen der genannten Affektionen anschließen. Sie zeigt im Grunde dieselben Störungen wie die akute Form, indes tritt die charakteristische Abduktionshemmung bald in den Vordergrund, die jetzt nicht mehr durch das mechanische und schmerzhafte Hindernis der geschwollenen Schleimbeutel, sondern nach Küster durch ihre Obliteration verursacht sein soll. Da die entzündlichen Veränderungen von den Schleimbeutelwandungen auf die Gelenkkapsel und die Unterlage des Deltamuskels übergreifen, so finden auch in ihrer Umgebung Adhäsionen und Schrumpfungen statt, die sich äußerlich durch Atrophie und Einsinken des Deltamuskels und der Schulterblattmuskulatur bemerkbar machen. Die Schmerzen sind bei der chronischen Form nicht mehr so intensiv, sollen aber, wie bei der akuten Bursitis, entlang dem Nervus cutaneus brachii medialis nach der Innenseite des Oberarms bis zum Ellenbogen ausstrahlen. Küster fand einmal den Nerven bei einer Sektion in Narben eingebettet, glaubt aber mit Recht, daß die Lage des Nerven so von den Schleimbeuteln getrennt sei, daß derartige Vorkommnisse sehr selten sein müssen, 
vielmehr der Schmerz als Irradiation wie der Knieschmerz bei Coxitis anzusehen sei.

Die chronische Form soll nach Aussage aller Autoren bei frühzeitig einsetzender medikomechanischer Behandlung stets heilbar sein, ihre Behandlung sich aber durch Monate hinziehen können. Mit der kurz skizzierten chronischen Bursitis subacromialis (subdeltoidea) wird im allgemeinen nach Vorgang D u plays die Periarthritis humeroscapularis identifiziert.

Wie schon gesagt, soll sie sich entweder im Anschluß an eine akut verlaufene Bursitis oder besonders gern als Komplikation von schweren Traumen der Schulter entwickeln. So traten die zuerst von Duplay mitgeteilten Fälle sämtlich nach Luxation des Humerus ein. Da die Hauptsymptome des Leidens in einer schmerzhaften Versteifung der Schulter vor allem im Sinne der Abduktion bestehen in Verbindung mit Atrophie des Deltamuskels, angeblich hervorgerufen durch Obliteration der Schleimbeutel, erwächst ohne weiteres die Frage, ob differentialdiagnostische Anhaltspunkte dafür zu erlangen sind, daß es sich wirklich um eine reine Bursitis handelt oder um sonstige Schädigungen des Spatium subdeltoideum.

Es ist einleuchtend, ja selbstverständlich, daß bei der innigen Benachbarung zwischen dem Spat. subdeltoideum mit dem Tub. majus und der Gelenkkapsel, ferner der direkten Kommunikation mit den sämtlichen Bindegewebsräumen der Schulterregion, dem Spatium subpectorale, supra- und infraspinatum (über den gleichnamigen Muskeln) und vor allem der Achselhöhle das Spatium subdeltoideum bei schwereren Läsionen des Humerus und Skapuloh u meralge lenks nicht unbeteiligt bleiben kann, $\mathrm{daB}$ es zu Zerreißungen, Quetschungen mit Blutungen an Ort und Stelle kommen muß. Es ist ferner einleuchtend, daß der Raum selbständig, ebenso wie das darunter liegende Tuberculum majus, Traumen insoweit ausgesetzt sind, als sie nicht durch ein kompensierendes Ausweichen des Schultergürtels abgefangen werden. Ich möchte darunter in erster Linie alle solche Traumen rechnen, die erfahrungsgemäß zur Luxation führen können, wie direkte Stauchung der Schulter von hinten außen oder heftiger Stoß und Fall auf den abduzierten außenrotierten Arm, wobei es zu einer Hebelwirkung des Tub. 
majus gegen das Akromion zunächst, gegen den Pfannenrand sekundär kommt und zur Quetschung der zwischenliegenden Weichteile. Auf die Wichtigkeit der Ausweichbewegung der Skapula in diesen Vorstadien der Luxation macht Fick aufmerksam.

Wenn es im Anschluß an solche Läsionen zu ausgedehnteren Organisationen in dem Raum kommt, so dürfte eine Unterscheidung von der chronischen adhäsiven Bursitis eine sehr heikle Aufgabe sein.

Es ist weiter $\mathrm{zu}$ bemerken, daß ein einwandfreier autoptischer Beweis für das Eintreten einer Obliteration von entzündlich veränderten Schleimbeuteln noch nicht erbracht ist. Ich schließe mich in dieser Hinsicht Schlesinger an, der meiner Ansicht nach mit Recht an den Duplayschen Fällen folgende Kritik übt: Duplay fand bei der Sektion dreier Fälle von den angeblich erkrankt gewesenen Schleimbeuteln keine Spur mehr, sondern lediglich einige durch das zur Lösung der Verwachsungen vorgenommene Débridement forcé zerrissene Stränge zwischen Kopf und Kapsel, die selber entzündlich verdickt waren. Schlesinger meint, daß ein völliges Verschwinden entzündeter Schleimbeutel ein Novum sein würde. Bekanntlich verdicken sich die Wandungen der Schleimbeutel unter Einwirkung chronischer Entzündung, und man findet meist mehrkammerige, mit mucinhaltiger Flüssigkeit gefüllte Hohlräume. Es scheint auch mir nicht gerechtfertigt, für die Schulterbeutel etwas anderes vorauszusetzen, sondern viel wahrscheinlicher, daß die Humerusluxation in der schon oben angedeuteten Weise eine allgemeine Schädigung des Spatium subdeltoideum und der Gelenkkapsel verursacht hat, die ohne Zuhilfenahme der Schleimbeutel das klinische Bild völlig erklärt, zudem auch in der Richtung ihm besser entspricht, als die gute Heilbarkeit durch Heißluft- und Übungstherapie eher verständlich ist, als bei den bekanntlich sehr schlecht zu beeinflussenden chronischen Schleimbeutelentzündungen.

Ich möchte daher hinter das Duplay-Küstersche Krankheitsbild der chronisch obliterierenden Bursitis ein Fragezeichen machen und viel eher vermuten, daß es sich bei den hierunter verstandenen Verletzungsfolgen um diff u se S c hä- 
digungen des Spatium subdelt oideum handelt, bei denen vielleicht die Zerstörung des subakromialen (und subdeltoiden) Sch leimbeutels eine Rolle spielt. Darauf lassen die Sektionsbefunde Duplays eher schließen, als auf eine chronische Entzündung der Bursae. In der Wirkung unterscheiden sich beide Arten der Erkrankung natürlich nicht, da sie beide die Gleitfähigkeit des subdeltoiden Raumes aufheben.

Im Interesse der möglichst exakten Abgrenzung der zirkumartikulären Prozesse von den intraartikulären möchten wir indes unbedingt an der Periarthritis humeroscapularis als besonderem Krankheitsbilde festhalten und darunter weniger verbindlich alle diejenigen Folgezustände stumpfer Läsionen der Schulter begreifen, die durch den charakteristischen Symptomenkomplex der Abduktionshemmung ohne nennenswerte Behinderung der übrigen Bewegungen, Atrophie des Deltamuskels ohne nachweisbare Beteiligung der Gelenkkapsel (Druckschmerz, Verdickung, Krepitation) auf eine zu Obliteration führende Schädigung des Spatium subdeltoideum hinweisen.

Derartige Fälle finden sich sicher in großer Zahl unter jedem größeren Verletzungsmaterial, während ich mich nicht erinnern kann, auch nur einmal die Annahme einer adhäsiven chronischen Bursitis habe machen zu müssen.

Auch die akute Bursitis subacromialis scheint doch nicht allzu häufig zu sein. Immerhin habe ich, seit ich mehr darauf achte, einige Fälle dafür angesprochen und möchte einen charakteristischen mitteilen, zumal sich mir bei ihm eine therapeutische Maßnahme bewährt hat:

F all r. E. Sch., 48jährige Ehefrau.

Bisher vollkommen gesund. Auch sonst nichts Krankhaftes zu finden. Kräftige, gut genährte Person.

Am 25. I. I9I4 morgens plötzlich ohne erkennbaren Anlaß heftiger Schmerz oben in der rechten Schulter (,,im Gelenk“). Schmerzen werden im Lauf des Tages heftiger und rauben ihr nachts den Schlaf, zumal sie nicht auf der rechten Schulter liegen kann. Der Schmerz konnte gelindert werden, wenn sie sich aufsetzte und den Vorderarm aufs Bein stützte. (Entspannung des subdeltoiden Raums.)

Am 26. I. ergibt die Untersuchung keine wesentliche Formveränderung an der erkrankten Schulter, lediglich starken Druckschmerz an der vorderen und äußeren Kontur des Akromions nach 
Die Arthritis acromio-clavicularis als wichtiges Glied in der Pathologie usw. 589

den angrenzenden Weichteilen hin. Unter Schmerzen sind die Abduktionsbewegungen in wesentlich geringerem Maße ausführbar als auf der linken Seite. Auch starke Einwärtsrotation ruft Schmerz hervor. Das Gelenk ist ganz frei von Druckschmerz und Schwellung.

Vor allem aus diagnostischen Gründen wird nun in die vermutlich erkrankte Bursa subacromialis eine I njektion von etwa $5 \mathrm{ccm}$ einer I proz. Novokain-Bikarbonat-Adrenalin. Lösung vorgenommen.

Sehr bald danach werden alle Bewegungen schmerz1 os ausführbar, im selben Ausmaß wie links. Am 27. I. berichtet die Frau sehr zufrieden, daß sie vorzüglich geschlafen habe, daß sie den Arm viel freier bewege, nur die seitliche Vertikalerhebung noch nicht ganz möglich sei. Der Druckschmerz ist verringert. Am 28. I. macht sie sich wieder selbst die Haare ohne Beschwerden. Kein Druckschmerz.

\section{Weiter glatter Verlauf.}

Trotz Fehlens lokaler Schwellung war der akut einsetzende, sehr schmerzhafte, auf die Subakromialgegend beschränkte Prozeß bei der umschriebenen Druckempfindlichkeit unter dem Akromialrand, der Hemmung der Abduktion des Oberarms als Bursitis subacromialis zu deuten. Die prompte Beseitigung der Schmerzen und Funktionsstörungen durch die Novokain-Injektion gab der Diagnose eine wertvolle Stütze. Wir möchten aber auch einen therapeutischen Nutzen dieses Verfahrens darin erblicken, daß die Beschwerden auch nachträglich nur in geringfügigem Maße wiederkehrten und die Affektion einen überraschend schnellen Heilverlauf nahm. Neben der stark suggestiven Komponente einer so schnellen Bekämpfung der lebhaften Schmerzen wird in solchen Fällen die Vermeidung jeglichen immobilisierenden Verba ndes einen günstigen Einfluß ausüben, wie sie unter der analgesierenden Wirkung der Injektion möglich wird. Ich habe diese Injektion auch in einigen anderen Fällen von fraglichen Schleimbeutelaffektionen (auch am Knie) angewandt und mich von ihrem diagnostischen und in obigem Sinne therapeutischen Wert überzeugen können.

Der Injektion eines Lokalanästhetikums kann selbstverständlich im Falle eines größeren Ergusses die Aspiration desselben vorangehen. Heineke erwähnt bereits, daß die Diagnose einer akuten Bursitis durch Punktion mit Troisquart gestellt 
worden sei, und Flint hat die Punktion mit nachfolgender Aspiration als ,a new and simple treatment" mit gutem Erfolg angewandt.

Es sei hinsichtlich aller der therapeutischen Erfolge, auch des unseren, ausdrücklich darauf hingewiesen, daß die akute Bursitis auch ohne derartige Eingriffe zunächst anscheinend schnell ausheilen kann, daß sie aber dazu neigen soll, später ins chronische Stadium überzugehen. Aus diesem Grunde scheint gerade die Vermeidung einer längeren Fixation, wie es durch ev. zu wiederholende Novokaininjektionen ermöglicht wird, von besonderem Nutzen.

Wir wollen das Thema der Bursitis nicht verlassen, ohne auf die von Alfred Stieda zuerst beschriebene, mit röntgenologisch nachweisbaren Veränderungen einhergehende Form einzugehen. Er fand in 8 Fällen (davon 6 Frauen) im Anschluß an mit aller Heftigkeit einsetzende Schmerzattacken und Bewegungsbeschränkung in ähnlicher Weise wie bei der Bursitis auf den anteroposterioren Röntgenbildern an der Außenseite des Humeruskopfschattens in der Höhe teils des Tuberculum majus, teils des Collum anatom., und noch weiter nach dem Akromion hinaufreichend den Humerusschatten begleitende, fleckig wolkige Schatten, die er zunächst als gichtische Ablagerungen in den Schleimbeuteln auffaßte. Diese gichtische Hypothese war vom röntgenologischen Standpunkt von vornherein recht zweifelhaft, da bekanntlich die Harnsäurekonkretionen entsprechend ihrer lockeren Zusammensetzung aus denselben organischen Elementen, wie sie die Weichteile ausmachen, für Röntgenstrahlen auch ebenso durchlässig sind wie jene, und sowohl bei der Gicht die Tophi sich nur durch Zerstörung des Knochengewebes markieren, als auch unter den Nierensteinen gerade die urathaltigen nicht zur Abbildung kommen, wenn sie nicht in höherem Grade kalkhaltig sind. So wurde denn auch bald, allerdings nicht aus röntgenologischen Gründen, sondern auf Grund von autoptischen Befunden diese Behauptung widerrufen (Bergemann und Stieda), und an Stelle der Harnsäure kohlensaurer und phosphorsaurer Kalk gesetzt. Die Befunde Stiedas fanden vielfältige Bestätigung besonders in den Mitteilungen von $\mathrm{Haenisch}$ und Prei- 
Die Arthritis acromio-clavicularis als wichtiges Glied in der Pathologie usw. 591

ser, ferner Blenke, Beltz, Lotsy, Immelmann, Holzknecht, Calatajud et Estopina u.a. Von Bergemann und Stieda sowie Haenisch wurden autoptische Befunde beigebracht, auf die wir noch zurückkommen müssen.

Trotz der zahlreichen Einzelbeobachtungen erhält man weder klinisch noch pathologisch-anatomisch ein klares Bild der Affektion, insbesondere bleibt das ätiologische Moment einigermaßen dunkel. In einer größeren Zahl von Fällen wird von vorangegangenem Trauma berichtet, einmal setzt die Krankheit danach mit ganz akuter Heftigkeit ein, das andere Mal schleichen sich die Beschwerden langsam ein, um erst im Verlauf von I bis 4 Wochen (Haenisch) die größte Intensität zu erlangen. In anderen Fällen fehlt jede nachweisbare Ursache, vereinzelt scheint Disposition zu Arthritis deformans zu bestehen (Preiser), die indes von anderen Autoren (Haenisch) wieder ganz von der Hand gewiesen wird. Sonstige Grundkrankheiten (Tuberkulose, Lues) wurden nicht gefunden.

Die Diagnose der „Bursitis calcarea“ kann nur mit dem Röntgenbilde gestellt werden. Indes gehen Röntgenund klinischer Befund keineswegs Hand in Hand. Bald fand man, wie schon Stieda in seiner ersten Arbeit mitteilt, die charakteristischen Röntgenschatten an einer völlig beschwerdefreien Schulter, bald trat mit dem Rückgang der Beschwerden auch ein promptes Kleinerwerden der Röntgenschatten ein, wobei das schnelle und vollständige Verschwinden der Schatten in wenigen Monaten entschieden als ein pathologisches Novum anzusehen ist. In anderen Fällen aber zeigt sich trotz erfolgreicher Bekämpfung der lebhaften Schmerzen und der Bewegungsstörung mit Hitzeapplikation, Massage und Übungstherapie keinerlei Veränderung der pathologischen Röntgenschatten.

Es ist mit Bestimmtheit daraus der Schluß zu ziehen, daß die $\mathrm{Kalkablagerungen} \mathrm{in} \mathrm{einer} \mathrm{größeren} Z$ ahl von Fällen nicht die Ursache der Beschwerden sind (Haenisch, Wrede). $\mathrm{DaB}$ die ganze Frage noch im Fluß ist, beweist die Auffassung Wredes, der auf Grund eines von ihm beobachteten und operierten Falles von Röntgenschatten an der bekannten Stelle, die sich als Kalkkonkremente in der Sehne des Supraspinatus erwiesen, das Vorliegen einer Bursitis calcarea in den 
bisher mitgeteilten Fällen sämtlicher anderer Autoren überhaupt anzweifelt.

Da von der angegriffenen Seite bisher eine Abwehr nicht erfolgt ist, verlohnt es sich, kurz die Argumente Wredes zu beleuchten. Vorangeschickt mag werden, daß der Wredesche Patient 76 jährig ist, während sonst durchweg jüngere Individuen befallen waren. (Haenisch z. B. zwischen 23 und 43 Jahren.) W rede schreibt: „Der breite Raum zwischen dem Schatten des Akromions und des Humeruskopfes wird nicht von dem Schleimbeutel, sondern abgesehen vom Knorpel des Humeruskopfes ganz allein von den Muskeln und Sehnenmassen des Supraspinatus eingenommen.“ „Die pathologischen Kalkschatten an der Schulter liegen aber bei guter Projektion of $\mathrm{t}$ deutlich so dicht dem Humeruskopf an, daß sie dem beträchtlich lateral gelegenen Schleimbeutel nicht angehören können."

Demgegenüber ist zu sagen, daß ein so wesentlicher prinzipieller Unterschied zwischen der Lage der Supraspinatussehne und der des Schleimbeutels nicht besteht, die ja direkt übereinander liegen, daß er bei der ungeheuer wechselnden Projektion des Röntgenbildes der Schulter ins Gewicht fallen kann, so daß man auch bei Durchsicht der Bilder der verschiedenen Publikationen bald Deckung der Schatten mit dem des Humerus, bald nähere, bald fernere Distanz findet.

Ferner ist doch vor allem ein Unterschied zu machen zwischen der Lagebeziehung der Schatten in der Höhe des Tuberculum majus und derjenigen weiter oben am Kopf und Akromion. Dem Tuberculum majus werden sowohl die von der Sehne ausgehenden Schatten, als auch die der Bursa einigermaßen dicht anliegen, wenn das Tuberculum majus durch die für solche Aufnahmen erforderliche Adduktions- und Außenrotationsstellung des Humerus an die Außenkontur zu liegen kommt. Oberhalb des großen Höckers aber, nach dem Akromion zu, wird stets eine größere Distanz sich bemerkbar machen, da sich hier Knorpel und Muskelmasse zwischenlegt; abgesehen davon, daß die zur röntgenologischen Darstellung des Spaltraums zwischen Akromion und Humeruskopf erforderliche kraniale Einstellung des Normalstrahls diejenigen Kalkschatten, die mehr zur vorderen Hemi- 
Die Arthritis acromio-clavicularis als wichtiges Glied in der Pathologie usw. 593

sphäre des Humeruskopfes Beziehung haben, auch dieser annähern muß.

Gerade auf den breiten Raum zwischen Akromion und Humeruskopf weist also Wrede zunächst hin, fragt dann weiter unten als zweiten Finwurf: „Warum dringt der Kalkbrei nicht einmal unter das Akromion in die Höhe?" Es liegt darin ein Widerspruch seiner Beweismittel und ein sachlicher Irrtum insofern, als sowohl $\mathrm{Stieda}$ in Fig. 5 und $\mathrm{I} 2$ seiner ersten Mitteilung, als auch Haenisch mit Fig. I I und I 5 (Tafel XXVIII) Bilder darstellen, auf denen das Hinunterkriechen unter das Akromion nicht deutlicher ausgeprägt sein könnte. Es kommt noch hinzu der Umstand, daß Bursa subacromialis und subdeltoidea nicht immer kommunizieren und daher in manchen Fällen die tiefere subdeltoide allein erkrankt sein kann, wie auch in einzelnen Fällen getrennte Verkalkungen in beiden Schleimbeuteln sichtbar waren.

Der Hinweis auf die unmögliche Verteilung des Kalkbreies in den Schleimbeuteln wird unserer Ansicht nach durch die. Tatsache hinfällig, da $B$ es sich niemals ausschließlich um eine lockere kalkige Ausscheidung in das Lumen, sondem um Kalkablagerungen um die fibrösen Fasern der Wạndungen der Bursa handelt, was der von F. Fraenkel in Haenischs operiertem Fall crhobene Befund deutlich besagt.

Zum Schluß der gewagte Finwand Wredes, die Autoren hätten bei ihren Operationen ,ein falsches anatomisches Bild auf Crund vorgefaßter Anschauungen" erhalten. Sie hätten unvermerkt dic zarten Wandungen der Bursa durchtrennt und die Schnenverkalkung dann für den Schleimbeutel angesehen! Wenn man auch zwei Argumenten Wredes beistimmen möchte, daß d:e Tatsache der Gelenkkapseleröffnung bei Herausnahme der Bursa überraschen muß, und da $B$ die Bursa subdeltoidea nicht gut durch eine Außenrotationsbewegung des Oberarmbeines zum Vorschein gebracht werden kann, wie Stieda und Bergemann beschreiben, so mußte sich Wrede doch das ganz einwandfrei für eine Affektion der Bursa sprechende pathol.-anat. Präparat vor Augen halten, über das Haenisch auf Grund der Untersuchung durch E. Fraenkel folgendermaßen berichtet: Ovaler Körper mit kalkhaltiger Höhle. Lichtung des Hohlraums im 
Maximum I $\mathrm{cm}$. Innenfläche mit kalkhaltigem Material bekleidet. Histologisch finden sich Bindegewebszüge; denen Kalk teils ein-, teils aufgelagert ist. Von dem Innenrand gehen kolbige Fortsätze aus, die teils gut erhaltene, teils verkümmerte Knorpelzellen, teils auch Knochen enthalten.

Es scheint uns danach die Beweisführung Wredes gegenüber den sämtlichen Fällen von Bursitis calcarea nicht geglückt und einstweilen noch kein Grund gegeben, das Vorkommen dieser Krankheitsbilder zu bestreiten.

Wir möchten aber dies Thema nicht verlassen, ohne kurz nochmal die Röntgentechnik solcher Fälle zu streifen. Es überrascht uns, daß die verschiedenen Publikationen stets nur anteroposteriore Aufnahmen bringen. Nach unserer Ansicht und eigenen Erfahrung müssen axiale Bilder manche Aufklärung hinzufügen können, es würden wahrscheinlich Teile der Konkremente vor dem Humeruskopf zur Abbildung kommen, und so ein näherer Anhaltspunkt über die Lagebeziehung in sagittaler Richtung zu erhalten sein; bei einigermaßen soliden Konkrementen würde aber auch ihre Form sichtbar werden, was ganz wesentlich zur Entscheidung der Frage Sehne oder Schleimbeutel beitragen könnte.

Sicher können diese Aufnahmen ausschlaggebend sein, wo die Differentialdiagnose zwischen Verkalkung und $\mathrm{Ab}$ bruch am Tuberc. maj. auf Grund des anteriopost. Bildes nicht sicher ist. Man würde den Schatten des Tuberculumfragments stets hinter dem Kopfschatten finden, die Bursaverkalkung wohl niemals. Vielleicht kann die axillare Projektion auch bei der Diagnose des akzessorischen Akromialknochens dienlich sein, da nach Lilienfeld zwischen diesem und der Bursitis calcarea Verwechslungen vorkommen sollen (Fälle von Lotsy und Haenisch).

Wir kehren von den verschiedenen Formen der Bursitis zu unserem Ausgangspunkte der Periarthritis humeroscapula ris zurück, unter deren Sammelbegriff einstweilen die akuten Entzündungszustände, die mit Kalkablagerung einhergehenden der Schleimbeutel, so wie die seltenen chronischen Bursitiden, vor allem aber die im Gefolge von schweren Schultertraumen auftretenden diffusen Verwachsungen des Spatium subdeltoideum 
zu verstehen sind. Es würde uns zu weit führen auf die ebenfalls hierher gehörigen Affektionen der mit der Gelenkkapsel in direktem Konnex stehenden Muskeln, Sehnen und Nerven einzugehen. Ich erinnere nur an das alte und immer seltener gewordene Bild derLuxation der Bicepssehne (Jarjaway), die soeben besprochene Verkalkung der Supraspinatussehne, AbriB der Sehnen des Supra- und Infraspinatus mit oder ohne Stücke von $T u b$. majus, die verschiedenen rheumatischen Affektionen der Muskeln, vor allem des Deltoideus, ferner die fragliche Neuritis des Nervus circumflexus (Desplats).

Es muß sehr auffallen, daß bei den zirkumartikulären Veränderungen immer nur auf die mit dem Spatium subdeltoideum in Beziehung stehenden Veränderungen Rücksicht genommen worden ist, wo doch die Funktionen des Schultergürtels mit der Articulatio scapulohumeralis und ihrem Gleitraume dem Spat. subdeltoideum nicht erschöpft sind, sondern ebensosehr in Abhängigkeit von der Intaktheit der dritten Etage, dem Schultergewölbe stehen. Wir möchten die Erklärung dieser überraschenden Tatsache in den einleitenden Worten Wredes zu der oben zitierten Arbeit finden. Wrede schreibt da: „Die Bewegungen des Armes in der Schulter gehen an drei Stellen vor sich:

I. in dem Gelenk zwischen Skapula und Humeruskopf,

2. in dem gelenkartigen Gewebsspalt zwischen dem von seinen Skapularmuskeln bedeckten Humeruskopf einerseits und dem Ligamentum coracoacromiale nebst der Unterfläche des

M. deltoideus andererseits,

3. zwischen Schultergürtel und Brustkorb.

Das ist richtig, nur fehlt die 4. Stelle im Akromioclaviculargelenk. Der Schultergürtel bewegt sich nicht nur gegen den Thorax, sondern auch in sich, die Skapula gegen die Clavicula. Diese Tatsache wird vernachlässigt, das Akromialgelenk zu sehr als Quantité négligeable behandelt, während ihm eine bedeutende Rolle im Mechanismus der gesunden und kranken Schulter zufällt. Es ist der eigentliche $Z$ weck dieser Mitteilung, hierfür einige Beweise zu erbringen.

Auch von a riat o m is che r Seite wurde der funktionelle Wert des Akromialgelenks lange Zeit hindurch verkannt. Die 
älteren Forscher beurteilen die Beweglichkeit des Schultergürtels nur einseitig nach dem Verhalten der Skapula. Winslow ließ das. Schulterblatt sich im wesentlichen nur um eine auf seinem Körper senkrecht stehende Achse drehen. Die Lage der Scapula war durch ihre Muskeln gegeben und das Schlüsselbein folgte zwangsweise ihren Bewegungen. Duchenne kannte zwei Drehachsen des Schulterblatts, einmal um den äußeren Winkel, wobei der Angulus nach außen, und zweitens um den inneren Winkel, wobei er nach innen sich bewegte. Henke berücksichtigte zum erstenmal die Gelenke des Schlüsselbeins bei seinen Untersuchungen und kam dabei zu der Anschauung, daß der Schultergürtel ein in sich feststehendes Gebilde sei, dessen Verschiebungen nur von der Beweglichkeit des Sternalgelenks abhängig seien, während diejenigen im Akromialgelenk als ganz unbedeutend eingeschätzt wurden. Henke hielt dabei an der alten Winslowschen Auffassung fest, wonach die Skapula vor allem um eine auf ihrer Mitte senkrecht stehende Achse drehbar sein sollte, die nach Henke vorn durch das Sternalgelenk ging.

Wie eine so grundfalsche Vorstellung sich festsetzen und viele Jahre hindurch die herrschende werden konnte, ist kaum verständlich, wenn man die cinfachsten Beobachtungen am Lebenden entgegenhält und bedenkt, daß eine am Schlüsselbein im festen Winkel verankerte Skapula durch die Anhebung des um das sternale Ende als Fixpunkt sich bewegenden akromialen Endes vom Thorax abgehebelt werden muß, wovon selbst beim extremen Achselheben nicht die Rede sein kann. Ias Schulterblatt ist von seiner Gleitbahn auf dem Thorax und vom Luftdruck zu sehr abhängig, als daß eine solche Entfernung vom Thorax möglich wäre (Fick). Erst H. v. Meyer schaffte hier Wandel. Er unterschied zwischen „Lageänderungen“ des Schulterblatts mit annähernd paralleler Verschiebung seiner Ränder und gleichzeitiger Funktion beider Claviculargelenke, wobei Bewegungen der Skapula nach oben und unten, vorn und hinten, außen und innen möglich sein sollten, und ,Stellungsänderungen" bei feststehendem Sternalgelenk, wobei nur das Akromialgelenk in Funktion trat, und zwar um drei Achsen: eine sagittale (Ab- und Adduktion), cine vertikale (Entfer- 
nung und Annäherung der Basis scapula an den Rumpf) und eine frontale (Abhebung und Anlegung des Angulus inf. scapulae an den Thorax).

Feinere Kenntnisse über die Beteiligung der beiden Schlüsselbeingelenke vermittelten die genauen Messungen Braunes und Fischers. Als wichtigstes Resultat ergaben ihre Untersuchungen, daß der Anteil des Akromialgelenks an der Beweglichkeit des menschlichen Inmerus durcha us nicht geringersei, als der des Sternoclaviculargelenks. Das letztere sollte sich vor allem bei den Bewegungen des Armes nahe der Frontalebene (Abduktion), jenes bei denen der Sagittalebene (Pendel- oder Sägebewegungen) beteiligen.

Fin sehr klares anschauliches Bild der wichtigen Verhältnisse brachte Gaupp, der durch die damals aktuelle Frage der Narkosenlähmung veranlaßt wurde, die vorliegenden Fragen zu prüfen. Fine Darstellung, die auch wohl durch die späteren Untersuchungen keine in praktischer linsicht wesentliche Abänderung erfahren hat.

Jedoch möchten wir die schr intercssanten Resultate der mühevollen Untersuchungen Molliers nicht übergehen, der an einem höchst sinnreich konstruierten, natürlich nur schematisch wirkenden bewegungsmechanischen Modell die Beziehungen der Schultermuskulatur zu den Gelenken des Schultergürtels prüfte: Nollier kommt zu folgenden Schlüssen: Schlüsselbein und Schulterblatt sind durch das sternale und akromiale Gelenk unter sich und mit dem feststehend gedachten Thorax nach allen Richtungen beweglich verbunden. Iie Bewegungen in den Gelenken, wie diese selbst sind streng auseinanderzuhalten, und so auch die Muskeln danach zu scheiden, ob sie auf ein oder das andere oder beide Gelenke einwirken. Danach teilt Mollier die Rumpfgürtelmuskeln in vier antagonistische Paare ein, die er mit II. v. Meyer als "Muskelschlingen“" bezeichnet:

I. oberer Abschnitt des 'Trapezius und Pectoralis minor (Heben und Senken im sternalen Gelenk),

2. mittlerer Trapezius und die obere und mittlere Portion des Serratus antic. major (Vor- und Rückwärtskreisen des akromialen Endes der Clavicula im Sternalgelenk), 
3. Rhomboidei und unterer Serratus (Schulterblatt schwingt im akromialen Gelenk wie ein Pendel hin und her),

4. Levator und unterer Trapezius (wirken auf beide Gelenke des Schlüsselbeins, da sie neben der auf- und abwärtsziehenden auch eine rotatorische Komponente besitzen).

Um dies Skelett gruppieren sich von selbst sämtliche Bcwegungskompositionen des Schultergürtels, deren Endzweck Mollier darin sieht, daB durch die Bewegungen im Akromialgelenk die Exkursionsweite des Skapulohumeralgelenks erhöht und durch das Sternalgelenk die Schwingungen des Akromialgelenks und Humeroskapulargelenks in die zweckmäßige Bahn verlegt werden, wodurch noch eine weitere Steigerung des Schwingungsausschlags erzielt wird.

Die Funktionsweise der Claviculargelenke steht natürlich in innigem Zusammenhang mit ihrem $\mathrm{Bau}$, wie wir ihn am eingehendsten in dem Standard-Work Ficks dargestellt finden; wir gehen nur kurz auf die uns hier interessierenden Verhältnisse des $\Lambda \mathrm{kromialgelenks}$ ein:

Das Gelenk ist der Untersuchung gut zugänglich, da es nur von den Ausläufern der Trapeziussehne, die zum Deltoideusansatz hin zieht und von der Haut bedeckt ist. Die Kapsel ist dorsal durch das besonders im hinteren Abschnitt starke Lig. acromioclavicul. verstärkt, während sie nach dem Spat. subdeltoideum hin zart und manchmal durchlässig sein soll. Poirier beschreibt cine größere „Schleimsackgeschwulst" nach unten hin als Ausstülpung des Gelenks.

Die Beschaffenheit des Gelenkbinnenraums ist sehr wechselnd, da sich zwischen die beiden Gelenkenden ein Zwischenknorpel einschiebt, der $z$ wischen einer kleinen von oben, unten oder der Seite eindringenden „Innenhautfalte“ und einem ganzen Meniscus, der zwei getrennte Gelenkspalte herstellt, die verschiedensten Übergangsformen zeigen, z. B. in Keil- oder Ringform auftreten kann. Die Knorpeloberfläche der Knochenenden ist hyalin, in der Tiefe ebenso wie an der Zwischenscheibe parallel gefasert.

Interessant und besonders für die Frakturdiagnose im Röntgenbilde wichtig sind die sehr seltenen Anomalien am Akromion. Nach Gruber verknöchert die $\Lambda$ kromionepiphyse in 
zwei Knochenkernen, einem der Basis, einem der Spitze, die etwa bis zủm i 7. Lebensjahr verschmelzen, mit der Spina bis zum 25. Lebensjahre. Spaltbildungen, die später sichtbar sind, beruhen auf der Persistenz der Epiphyse, die entweder knorpelig bleiben oder durch besonderen Gelenkspalt mit der Spina in Verbindung stehen kann. Gruber unterscheidet ein Os acromiale terminale, das häufigere, meist dreieckig geformte, und $O s$ acromiale basale. Ludewig fand unter Leitung Lusch$\mathrm{kas}$ ein Os acromiale bei einer Leiche, die auf der anderen (rechten) Seite einen mit Pseudarthrose geheilten Bruch des akromialen Clavicularendes aufwies. Wir glauben, in unserem Fall Io auf den Röntgenogrammen (Fig. 8 und 9) neben arthritischen Veränderungen im Akromialgelenk eine akzessorische Epiphyse, einen „Akromialknochen“ erkennen zu sollen (S. 624), wenngleich eine sichere Abgrenzung von einer Fraktur am $\Lambda$ kromion nicht möglich ist.

Neben diesen soll nach Lilienfeld eine eigentliche Varie$t a ̈ t$ in Form eines isolierten Knochens in der Nähe des Akromialgelenks vorkommen, den er als Os acromiale secundarium bezeichnet, und der dadurch Bedeutung erlangt, daß er als „Entartungsform" (Pfitzner) wandert, z. B. in dem von Lilienfeld beobachteten Fall dicht am Tuberculum majus lag, wo er leicht mit einem Fragment, Callus, Schleimbeutel oder Sehnenkonkrement verwechselt werden kann. Eine solche Verwechslung nimmt Lilienfeld in einem Fall von Haenisch und Lotsy an.

Dic dem Akromialgelenk eigene Form ist nach Fick die des ,Eigelenks“, dessen lange Krümmung von vorn nach hinten, dessen schärfere von oben nach unten verläuft. IJa das Gelenk nicht rein sagittal steht, sondern einmal von hinten medial nach vorn lateral und zweitens von außen oben nach innen unten geneigt, liegen die Krümmungsachsen nicht in den einfachen Körperrichtungen, sondern schräg dazu: es kommen so die z wei Ha up tbewegungendes Schulterblattes im $\Lambda \mathrm{kromial-}$ gelenk zustande:

I. um die vertikale Achse - die mit ihrem oberen Ende lateral-dorsal geneigt ist -- in der langen Eikrümmung vón vorn nach hinten:

Drehung der Skapula mit der Spitze nach außen vorn oben, 
mit dem Proc. coracoid. nach oben hinten, und mit der Pfanne nach oben, so da $B$ bei ausgiebigen Bewegungen das Schulterblatt nahezu quer steht mit vertikaler Gräte; 2. um die sagittale, auf der vorigen senkrecht stehende, also mit ihrem hinteren Ende medial und kaudal geneigte Achse - in der kurzen Fikrümmung von oben nach unten:

Das Schulterblatt verschiebt sich vorwärts, dreht sich mit seiner Spitze etwas vorwärts und lateral, so daß die Pfanne schräg nach oben sieht.

Die unter I resultierende Bewegung ist die hauptsächlichste und ausgiebigste und findet statt bei der vertikalen Erhebung des Oberarmes, die unter 2 ist weit weniger umfang. reich. Sic tritt ein, wenn das akromiale Ende des Schlüsselbeines vertikal ansteigt (beim Achselheben) und ermöglicht es, daß die Skapula dem Brustkorb adaptiert bleibt, annähernd parallel in die Höhe steigt.

Da nun einmal die Eiform nicht immer streng gewahrt bleibt, das Gelenk vielmehr nicht selten gradlinig ist, da ferner durch die Knorpeleinlage und die zur Länge ihrer Hebelarme kleinen Gelenkflächen eine recht freie Beweglichkeit garantiert ist, sind zahlreiche Übergangsbewegungen ausführbar, die das Gelenk zu einem ,Wackelgelenk" stempeln (Fick), das auch in gewissem Grade Bewegungen zuläßt, die den Eikrümmungen entgegenlaufen, wie z. B. um rein vertikale Achsen, wobei vorwiegend eine Vergrößerung oder Verkleinerung des Horizontalwinkels zwischen Spina scapula und Clavicula statthat.

Als praktisch bemerkenswertestes Ergebnis der mechanischen Analyse des Akromialgelenks ergibt sich die Freiheit des Gelenks nach allen Richtungen, und ferner die Tatsache, daß die Bewegungen der Schulterpfanne in der Richtung von vorn nach hinten in weiterem Maße ausführbar sind, als nach der Seite. Daher werden die Bewegungen des Vorderarmes nach vorn und hinten durch das Akromialgelenk mehr gefördert als die nach der Seite.

Die erforderliche Frgänzung erfährt die Funktion des Akromialgelenks durch das Sternalgelenk, das vor allem, wie die Messungen Braunes und Fischers ergeben, die Armbewegungen in der Schulterblattebene, also die seitlichen, fördert. 
An der Hand der anatomischen Tatsachen sind die am Lebenden leicht nachzuprüfenden Bewegungstypen des $\mathrm{Schulterblatts} \mathrm{im} \mathrm{Akromialgelenkgut} \mathrm{verständlich,} \mathrm{wie} \mathrm{sie}$ einmả die selbständigen Aktionen des Schultergürtels und zweitens die dic Armfunktionen fördernden Schulterbewegungen begleiten.

Bei der folgenden Darstellung dieser typischen Bewegungen im Akromialgelenk werden wir stets von einer Mittelstellung des Schultergürtels unsern Ausgang nehmen, bei der das Schulterblatt die Mitte zwischen Frontal- und Sagittalebene hält. Es ist bekannt, daß diese Stellung keineswegs bei allen Menschen auch nur annähernd die Normalstellung ist, daß das Schulterblatt bei militärisch geschulten Leuten sich mehr der Frontalebene nähert, nach hinten gezogen wird, bei schlapper Haltung nach vorn rutscht, sich mehr in die Sagittale einstellt.

Zunächst die selbständigen Aktionen des Schultergürtels, teils Ausdrucksbewegungen (fragendes oder verächtliches Achselzucken, Hoch- und Rückziehen bei Angst und Schrecken usw:), teils ein Mittel, die Körperform beschränkten Raumverhältnissen anz upassen (An- und Vorzichen der Achseln im Gedränge, ähnlich beim Schwimmen), oder das Gleichgewicht zu regulieren, schließlich die aktiven Kraftäußerungen der körperlich arbeitenden Bevölkerung, besonders des Transportarbeiters und anderer Lastträger: das Heben der Schultern zum Tragen, das Vorschieben beim Anstemmen, das Rückwärtsschicben beim Tragen auf dem Rücken zwischen den Schulterblättern.

Bei der Gelegenheit sei darauf hingewiesen, daß bei allen diesen Aktionen die Lasten nicht dirckt a uf die Schulterhöhe (Akromion und Clavicula), sondern von vorn außen oder hinten dagegen gelegt werden, wobei im ersten Falle vor allem das Tuberculum majus mit dem bretthart kontrahierten und schützenden Deltoideus in Funktion treten. Es kommt dabei nur zu einem Anstemmen an der vordereh und äußeren rauhen Kontur des Akromions.

Die selbständigen Achselbewegungen, die ja ebenfalls der Verlagerung der Schulterpfanne dienen und insofern natürlich von den Hilfsbewegungen nicht prinzipiell zu trennen sind, erfolgen vorwiegend im Sternalgelenk, was ja aus 
der von Mollier klar fixierten Aufgabe dieses Gelenks von selbst hervorgeht. Indes begleiten sie ganz typische Verschiebungen der Clavicula im Akromialgelenk. Beim Erheben der Schulter (Achselzucken) $\mathrm{nach}$ oben erfolgt eine Steilstellung des Schlüsselbeins, das sich dabei um die sagittale Achse im Sternalgelenk bewegt, während die Skapula eine Parallelverschiebung aufwärts (Lageänderung nach H. v. Meyer). erfährt, oder doch nur eine viel geringere Drehung mit dem unteren Winkel nach auswärts und oben vorn, als es der Kreisbewegung des akromialen Endes der Clavicula entspricht. Wir haben es mit dem Typus 2 der Akromialgelenkbewegung zu tun, Drehung um die sagittale Achse unter Einwirkung der. Schwere des Armes (siehe Seite 600 unter 2).

Die Vor-und Rückwärtsbewegung der Achsel wird vor allem bewirkt durch eine entsprechende Bewegung im Sternalgelenk um die vertikale Achse. Dabei aber führt die Skapula Bewegungen aus, die, wie $F$ ick annimmt, den $Z$ weck haben, eine für ihre Bewegungsfreiheit ungünstige Einstellung der Schulterpfanne zu verhindern. Bei der Bewegung nach vorn erfolgt eine Drehung im Akromialgelenk nach hinten, wodurch sich der „skapuloclaviculare Horizontalwinkel" verkleinert, bei der Achselverschiebung nach hinten tritt umgekehrt eine Vergrößerung des Winkels ein. Es behält also die Cavitas glenoidalis scapulae auf diese Weise ihre Stellung nahezu bei.

Während die bisher angeführten Bewegungen mit denen des Oberarmes nur in lockerem Zusammenhang standen und ganz unabhängig davon stattfinden können, handelt es sich bei den nun folgenden um direkt unter dem EinfluB der Armbewegungen eintretende Verschicbungen, vor allem im Akromialgelenk.

Sowohl bei den seitlichen wie vorwärts gerichteten Elevationsbewegungen des Armes bleibt das Schlüsselbein bis zur Erreichung einer beträchtlichen Höhe von I40 bis I 50 Grad in seiner Lage. Bis dahin erfolgen lediglich Stellungsänderungen der. Skapula im Akromialgelenk, und zwar nach dem Typus I um die vertikale Achse, wobei die Skapula sich im wesentlichen um eine sagittale Achse dreht, so daß der untere Winkel sich nach aủßen vorn und oben verschiebt. 
Diese Rotation der Skapula beginnt bei verschiedenen Individuen zu verschiedenen Zeitpunkten. Es kann unsererseits nicht zugegeben werden, wie von anatomischer Seite gewollt wird, daß sie immer schon unterhalb der Horizontalen anfängt. Andererseits ist auch das Gegenteil unrichtig, eine Gelenkversteifung stets schon dann diagnostizieren zu wollen, wenn unterhalb der Horizontalen die Skapula mit dem Humerus „mitgeht“. Es gibt sicherlich eine große Zahl Menschen, bei denen schon bei einem Humeroskapularwinkel von 6o Grad die Rotation des Schulterblatts - in erheblichem Maße - einsetzt. Ganz leichte Verschiebungen bemerkt man meist schon vorher, und Miramond de Laroquette äußert sich interessanterweise auf. Grund von radiographischen Studien dahin, daßschon im Beginne der Abduktionsbewegung des Armes die Mitbewegung der Skapula festzustellen sei. Jedenfalls hat er darin recht, daß die Bewegungen von Arm und Schulterblatt stets $H$ and in $H$ and gehen, nicht etwa getrennt aufeinanderfolgen, so daß etwa zunächst ein großer Teil der Schultergelenkbeweglichkeit erschöpft wird, und dann erst die des Akromialgelenks cinsetzt.

Läßt man zunächst den Arm schlaff hängen, ihn dann abduzieren, so fühlt man, wie sich die Skapula in ihrem „,Muskelgelenk“ (Fick) feststellt, nachdem sie manchmal zunächst unter der Schwere des Armes etwas wirbelwärts ausgewichen ist. Darauf beginnt nicht selten sofort ein ganz leichtes Mitdrehen der Schulterblattspitze. Indes wird man wohl nicht so leicht dies elastische aktive Rotieren des Schulterblatts mit dem $z$ wangsmäßigen harten "Mitgehen“ verwechseln können.

$\Lambda$ bduktions- und Vorwärtsbewegungen verhalten sich auch in dieser Hinsicht identisch. Erst am Ende dieser Bewegungen beobachtet man eine Lageveränderung des Schlüsselbeins, das bis dahin stillgestanden hat. Waldeyer hat nachgewiesen, da $B$ zur vollständigen Horizontalstellung der Schultergelenkpfanne eine Bewegung des Schlüsselbeins nach hinten erforderlich sei. Sie ist stets deutlich zu verfolgen, meist verbunden mit einer Hintüberdrehung der Clavicula um die Längsachse mit der Vorderfläche in der Richtung aufwärts, gleichermaßen ob 
Abduktion oder Vorwärtselevation des Arms. Das Einsetzen der Rückwärtshebung des akromialen Schlüsselbeinendes erfolgt manchmal schon bald nach Überschreiten der Horizontalen.

Bei der Rückwärtsbewegung des Armes, die bis zum rechten Winkel, sehr häufig darunter, selten wesentlich höher ausgeführt werden kann, dreht sich die Skapula im entgegengesetzten Sinne mit dem Angulus inferior auf- und einwärts. $\mathrm{Zu}$ letzt tritt eine geringe Vorwärtsbewegung der Clavicula mit Rotation um die Längsachse über vorn nach unten ein, die ausgiebiger zu sein pflegt, als die vorhin erwähnte.

Die Rotationsbewegungen des Oberarms um die Längsachse werden nicht von typischen Bewegungen des Schultergürtels begleitet, indes fühlt man bei der extremen Einstellung Hebelwirkungen im Akromialgelenk, wodurch bei der Einwärtsrotation ein Heraustreten. des akromialen Schlüsselbeinendes nach vorn und oben, bei der Auswärtsrotation mehr ein Verschwinden des Endes im Akromialbogen zu bemerken ist.

Die Frörterung des Schultergürtelmechanismus läßt die große funktionelle Bedeutung des Akromialgelenks zur Genüge erkennen, das an allen Bewegungen des Arms und der Schulter teilnimmt. Mit der Inanspruchnahme eines Gelenks steigt seine Abnutzung und Läsionsexposition. Es kann nicht mehr wunder nehmen, daß es auch in der Verletzungspathologie der Schulter eine größere Rolle spielt, als ihm bisher zuerkannt worden ist. Die Kenntnisse seiner Funktionen wird uns klaren Einblick in die Symptomatik der Erkrankungen des Gelenks geben.

Wir beabsichtigen keineswegs eine vollständige Klinik der Erkrankungen des Akromialgelenks zu schreiben, vielmehr nur auf die Beteiligung dieses Gelenks an den Folgen stumpfer Verletzungen der Schulter an der Hand mehrerer einschlägiger Fälle hinzuweisen und $\mathrm{zu}$ versuchen, gewisse Erkrankungstypen herauszuschälen.

Mitteilungen in dieser Richtung sind höchst spärlich. Hueter erwähnt nur die pyämische Entzündung des Gelenks, die aber „noch geringere Bedeutung" habe, als die des Sternoclaviculargelenks, immerhin hat er schon Resektionen des Akromialgelenks ausgeführt, „wobei es sich indes weniger um das Gelenk, 
als um die erkrankten Knochenpartien des Akromions und der Clavicula handelte". Hueter weist bei dieser Gelegenheit darauf hin, daß vom Akromialgelenk aus die darunter befindliche „synoviale Höhle“ mit vereitern und infolge deren Ausdehnung eine Schultergelenkvereiterung vorgetäuscht werden kann, die zur Resektion verleitet. „Chronischer Druckreiz durch Tragen von Lasten bringt nur selten Quetschung des Gelenks, mehr Bildung von subkutanen Schleimbeuteln hervor." Hueter meint damit die Bursa subcutanea acromialis, die auch Vogt erwähnt, indem er schreibt, die stets präformicrte Bursa acromialis sei bei allen Lastträgern vergrößert, ,nur einmal fand ich bei einem älteren Herrn diesen Schleimbeutel von voluminöserem Umfang infolge arthritischer Ablagerung ..." Diese Bemerkung läßt darauf schließen, daß Vogt hier eine chronische, entzündliche Erkrankung des Akromialgelenks beobachtet hat. Sie interessiert uns aus dem Grunde besonders, weil wir einen identischen Fall (Fall 12) sahen, bei dem die Exstirpation des Beutels mit Gelenkresektion ein befriedigendes Resultat zeitigte. Eine mit chronischer Arthritis im Akromialgelenk verbundene entzündliche Schwellung des subkutanen Schleimbeutels finden wir auch in Fall 5, möglicherweise auch Fall i 4 .

Sehr beachtenswert ist die Mitteilung Bährs über die traumatische Diastase des Akromioclaviculargelenks, als einem ,ziemlich häufigen, scharf zu charakterisierenden Krankheitsbild, das nicht mit der inkompletten Luxation zu verwechseln ist, da die Clavicula noch ziemlich fest im Gelenk haftet". Der Bährsche Fall ist folgender :

33jähriger Mann. Kontusion der rechten Schulter. Einen Monat darauf Schmerz beim Einstecken der IIand in die Tasche und Einstemmen in die. Seite. Schulterform normal. „Gelangt der Arm nach Erhebung über die Horizontale wieder etwas unterhalb derselben, so wird ein lautes „,knupsendes“ Geräusch hörbar. Dasselbe ist auf das Acromioclaviculargelenk zu lokalisieren, und man kann fühlen, wie das Akromion mit dem Geräusch mit einem Ruck unterhalb des Schlüsselbeins hervorspringt."

Wir werden sehen, daß der Bährsche Fall den unseren sehr nahe kommt und manche Erscheinungen bietet, die wir als charakteristisch für die Akromialgelenkserkran- 
kungen überhaupt ansehen möchten. Freilich legt Bähr das Schwergewicht auf die Diastase des Gelenks, deren Diagnose sich stützen soll auf das Verschwinden des Akromions unter der Clavicula bei der Abduktion und Wiederhervortreten bei der Adduktion. Wir haben derartige Beobachtungen, die für die Symptomatik des Krankheitsbildes entscheidend gewesen wären, nicht gemacht.

Ganz verstreut findet man noch einige auf unser Thema hinweisende Bemerkungen in der Literatur, soweit wir sie übersehen, die aber interessant genug sind, sie mitzuteilen. Gras. hey bildet in seinem Atlas chirurgisch-pathologischer Röntgenbilder einen Fall der nicht ganz seltenen Frakturen am äußeren Claviculaende $a b$ (Bild I86) und bemerkt dazu: ,Klinischer Nachweis der frischen Fraktur nicht schwer, doch kann empfindliche Schwellung und (weiche) Krepitation auch bei Distorsion des Akromioclaviculargelenks vorhanden sein". Grashey legt also zum ersten Male den Nachdruck auf die Gelenkerkrankung, während z. B. Köhler in seinem Lexikon ähnlich wie $\mathrm{Haenisch}$ von zackigen, höckrigen, unscharfen Appositionen an Clavicula und am Akromionende, ,bei chronischer Arthritis und in der späteren Folge von Unfällen" ganz allgemein spricht, ohne ausdrücklich auf das Akromialgelenk dabei hinzuweisen.

Thiem läßt sich über unseren Gegenstand folgendermaßen aus: „Nach Anbrüchen oder starken Knochenhautquetschungen am äußeren (und inneren) Ende des Schlüsselbeins zurückbleibende Wirkungen bedingen in der Regel ebensowenig eine nachhaltige Störung, wie die Verschiebungen (Subluxationen) in den genannten Gelenken." Wir werden an unseren Fällen zeigen, daß diesen Folgezuständen doch in der überwiegenden Mehrzahl größere Bedeutung beizumessen ist. Wenn Thiem fortfährt: „Zuweilen findet man bei diesen Verletzungen aber chronische Entzündungen in den Schlüsselbeingelenken, die sich durch deutliche Reibegeräusche kundgeben und bei langdauernden anstrengenden Bewegungen Schmerzen machen", so darf man vermuten, daß er schon ähnliche Beobachtungen gemacht hat, wie sie im folgenden mitgeteilt werden sollen.

Da uns eingehendere pathologisch-anatomische Befunde noch 
nicht zur Verfügung stehen, gründet sich die folgende Einteilung im wesentlichen auf klinisch-röntgenologische Tatsachen.

\section{Einteilung der Fälle:}

I. Akute (subakute) traumatische Arthritis ohne röntgenologischen Befund (Fall 2-5).

II. Chronische traumatische Arthritis

a) bei nachweisbarer Fraktur am akromialen Ende des Schlüsselbeins (Fall 6 und 7),

b) ohne erkennbare Fraktur (Fall 8-Io).

III. Arthritis chronica deformans

a) nach Trauma (sekundär) (Fall I I),

b) ohne Trauma (primär) (Fall $12-\mathrm{I} 4$ ).

I. Akute (subakute) traumatische Arthritis ohne röntgenologischen Befund.

Fal1 2. L. A., 63jähriger Stenotypeur.

Ist am 26. III. durch Stolpern mit den Händen aufs Trottoir gefallen und hat sofort heftige Schmerzen im ganzen linken Oberarm gespürt. Er war I4 Tage zuvor schon einmal in ähnlicher Weise gefallen, hatte auch damals Schmerzen, konnte aber weiter arbeiten, insbesondere auch feilen, hobeln, sägen und tragen. Nach dem 2. Fall aber war es ihm unmöglich zu arbeiten. Er wurde dann 6 Wochen lang ohne wesentlichen Erfolg massiert und medikomechanisch behandelt, nachdem etwa 4 Tage lang eine Feststellung durch Desaultschen Verband vorgenommen war.

Befund bei der ersten Untersuchung: Alle Bewegungen mehr oder weniger schmerzhaft. Seitliche Erhebungen bis 60 Grad möglich. Stärkere Einwärtsdrehung schmerzhaft, so daß die Hand nicht auf den Rücken fassen kann. Krepitation im linken Akromialgelenk ohne wesentliche örtliche Veränderungen. $\mathrm{R}$ ö $\mathrm{t}$ g e n b i ld e r zeigen beiderseits annähernd gleiche normale Verhältnisse; vielleicht ist die Begrenzung der Gelenkenden auf der kranken (linken) Seite nicht ganz so scharf.

Nach 2 Monaten vergeblicher Behandlung wird am 2o. V. das linke Akromialgelenk reseziert und der Defekt durch einen gestielten Fettlappen aus dem Subkutangewebe der Nachbarschaft gefültt.

Glatte Heilung der Wunde unter sechstägiger Fixation mit Desaultschem Verband. Schmerzen lassen bald unter Übungen und Massage nach. Wird am 2. VIII. aus der Behandlung entlassen. Kann den Arm bis zur Horizontalen erheben. Schmerzen sind wesentlich vermindert, so daß er seine Arbeit wieder aufnehmen kann. 
Die Untersuchung des Präparats zeigt, daß nur kleine Flächen etwas glatteren Knorpels sichtbar sind, im übrigen aber beide Gelenkenden von einer gelblichen feinzottigen Auflagerung bedeckt sind, unter der man bei der Durchschneidung die Knorpelschicht erkennt. Von der ventralen Seite her schiebt sich eine prismenähnlich geformte Scheibe in den Gelenkspalt ein, die eine faserige Oberfläche aufweist.

$\mathrm{H}$ is to log is ch fällt bei den fronta len Schnitten vor allem ein tiefer Knorpeldefekt am dorsalen Rande des Schlüsselbein. endes auf, der durch zellreiches, streckenweise auch gefäßreiches, feinfaseriges Bindegewebe geglättet und àusgefüllt ist. Auch auf der gegenüberliegenden Seite zieht sich ähnliches Gewebe pa n n u s artig über den durchweg faserigen Knorpel. Rein hyaliner Knorpel ist nicht zu sehen. Die Oberfläche der Gelenkflächen ist mehr oder weniger aufgefasert. Infiltrationen fehlen. Unter dem Defekt finden sich an umschriebener Stelle Knorpelzellwucherung als Andeutung von Regenerationsvorgängen.

Die oberflächliche Knochenlage des Akromions ist in lebhaftem Ersatz begriffen, während man nur in sehr geringer Zahl Osteoklasten findet, der Gefäßreichtum ist nicht ungewöhnlich und nur in den zu äußerst gelegenen Maschen der Markhöhle zart fibröses Mark, sonst, soweit untersucht, nur Fettmark vorhanden. Das Verhalten des Schlüsselbeinendes ist etwas different. Hier findet man nicht die dichten Osteoblastenreihen der Gegenseite, vielmehr zahlreichere Osteoklasten, ferner reichlicher fibröses Mark und sehr große prallgefüllte Gefäßlumina.

Die ventrale. Einschiebung besteht ebenfalls aus Fas erknorpel, der eine ganz auffallende Zerklüftung aufweist.

$\mathrm{Nachuntersuchung}$ am 27. I. 19r4: L. ist sehr zufrieden, gibt nur an, daB er gelegentlich einen vorübergehenden, nicht sehr heftigen Schmerz an der Operationsstelle habe, der mit dem früheren Schmerz nicht zu vergleichen sei. Der Resektionsdefekt ist in Form einer Delle deutlich fühlbar. Das Clavicularende springt etwa $1 / 9 \mathrm{~cm}$ nach oben vor. Die Niveaudifferenz verschwindet beim Heben der Schulter, wobei der Spalt deutlicher wird, er beträgt mehrere Millimeter. Das Clavicularende ist nicht empfindlich und zeigt dieselbe elastische Beweglichkeit wie das rechte. Die bogenförmige, nach hinten konvexe, $8 \mathrm{~cm}$ lange Operationsnarbe beginnt an der hinteren Kante des Gelenks und endigt etwas unterhalb des äußeren Randes des Akromions. Sie ist weich, verschieblich und unempfindlich. Der linke Arm' wird nahezu ebensoweit erhoben, wie der rechte, wenn auch nicht ganz so leicht wie dieser. Die mit den Oberarmelevationen verbundenen Bewegungen des Schlüsselbeins sind links etwas ausgiebiger als reçhts. Bei Rotationsbewegungen fühlt man in der Gegend des neugebildeten Gelenks feines Knirschen. Auf dem 
Die Arthritis acromio-clavicularis als wichtiges Glied in der Pathologie usw. 609

Röntgcnbild (Fig. I) sieht man einen scharf konturierten keilförmigen Gelenkspalt. Ein Teil seiner Begrenzungen fällt allerdings in die Schatten der Gelenkenden. Hier fehlt wohl noch stellenweise die Corticalis.

\section{Zusammenfassung:}

Nach einem indirekten Trauma setzen sofort heftige Schmerzen ein, die eine Unterbrechung der Arbeit herbeiführen und sich deutlich auf das Akromialgelenk lokalisieren. Kein Röntgenbefund. Diagnose: Traumatische Arthritis acromioclavicularis. $2 \frac{1}{2}$ Monate lang vergebliche mediko-

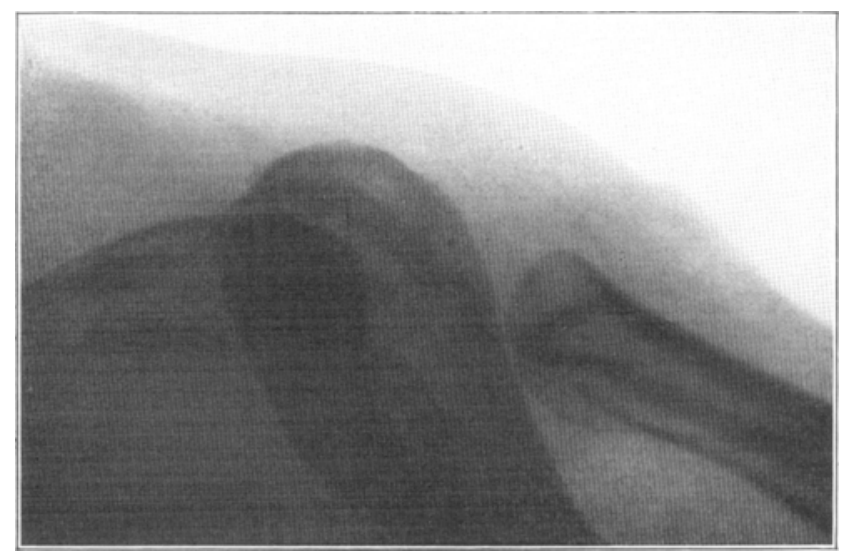

Fig. I,

mechanische Behandlung. Dann bringt Resektion des Gelenks eine prompte Beseitigung der Beschwerden, die nach 8 Monaten noch anhält. Nur leichte Schwäche der vertikalen Elevation bemerkbar und vereinzeltes Auftreten von Schmerzen. Das Röntgenbild (Fig. I) zeigt cinen breiten glattrandigen Gelenkspalt.

Das bei der Resektion gewonnene Präparat ist wegen des Fehlens normaler Vergleichspräparate mit äuBerster Reserve zu beurteilen. Doch darf man insofern einen positiven Befund daraus entnehmen, als ein sicherer, ziemlich bedeutender Knorpeldefekt am Schlüsselbeinende vorliegt, als hier und auch an anderen Stellen der Gelenkflächen pannusartige 
Bindegewebswucherung sich über den Knorpel gelegt hat, die wohl gewiß nicht in den Bereich des Physiologischen gehört. Inwieweit aber die unebene aufgefaserte Oberfläche, die Auffransung, insbesondere des Zwischenknorpels und das Fehlen hyalinen Knorpels krankhaft ist, kann erst nach eingehenden normalhistologischen Studien entschieden werden.

F a 11 3. M. H., Gojähriger Maurer.

Am 22. VII. IgI3 fiel M. infolge Ausgleitens beim Ausheben einer Mauer mit einer Brechstange rücklings auf die rechte Schulter. Konnte vor Schmerzen nur noch $1 / 2$ Stunde arbeiten, dann den Arm nicht mehr bewegen. Wird zunächst 4 Wochen lang mit Einreibungen und Elektrizität behandelt, dann mit Massage und Übungen, w's. bei allmählich Besserung der Beweglichkeit eintritt. Vorübergehend leichte Arbeit im Laufe des Dezember. Im Januar wieder vermehrte Schmerzen in der Schulter und Rentenanspruch. Klagt über Schwere des Arms und Schmerzen beim Anheben, besonders nach der Seitc.

Erste Untersuchung am 7. III. I9I4: Will bei der Arbeit immer noch beträchtliche Schmerzen haben, die ihm auch nachts den Schlaf rauben, sobald er sich auf die rechte Seite legt. Es machen ihm besonders die Bewegungen beim Mörteln und beim Reiben an der Decke, wobei die Schulter stark gehoben und der Arm gedreht werden muß, Schmerzen und Ermüdung. Die Schlüsselbeine springen beiderseits etwas stärker vor. Formveränderungen sind nicht nachweisbar, auch kein deutlicher Unterschied bei der Betastung der Gelenke. Nur Druckschmerz am Akromialgelenk und auf der Vorderfläche des Humeruskopfes ausgesprochen, der aber ebenso stark ist, wenn der Deltoideus entspannt ist, wie wenn er sich beim Vorwärtsheben stark kontrahiert. Die Achselerhebung ist rechts $8 \mathrm{~cm}$, links $10 \mathrm{~cm}$ ausführbar, und strengt rechts etwas mehr an. Dabei sinkt beiderseits das Schlüsselbeinende ins Gelenk ein. Beim Rückwärtsschieben der Achsel Schmerz und Spannung, die am vorderen Deltamuskel lokalisiert wird. Beide Bewegungen erschwert, sehr unbeholfen, während sie links ganz frei und leicht sind. Beim seitlichen Erheben des rechten Arms vom Winkel 65 Grad örtlich umschriebene Krepitation im Gelenk, deren Zusammenfallen mit dem Beginn der Abduktion der Scapula fühlbar ist. Sie fehlt auf der linken Seite. Die vertikale Erhebung des Arms ist zwischen I25-30 Grad möglich, links bis I70 Grad. Bei häufigen Abduktionsbewegungen rechts Schmerzen. Die Vorwärtserhebung des rechten Humerus geht bis I40 Grad, links bis I60 Grad. Beim Herunterlassen des rechten aus der Horizontale fühlt man etwas härtere Krepitation am Akromialgelenk. Schmerzen nur bei extrem vertikaler Erhebung. Erhebung des Arms nach hinten rechts bis $50 \mathrm{Grad}$, links bis 55 Grad. Keine wesentliche Be- 
Die Arthritis acromio clavicularis als wichtiges Glied in der Pathologie usw. 6 I I

hinderung. Beim starken Außenrotieren Knirschen und mäßige Schmerzen. Keine Atrophie.

$$
\text { Umfangsmaße: }
$$

Am Ansatz des Deltamuskels

Oberarm Io $\mathrm{cm}$ über dem Speichenköpfchen

Vorderarm $4 \mathrm{~cm}$ unter demselben

$\begin{array}{cc}\text { rechts : } & \text { links : } \\ 28,0 & 28,5 \\ 25,0 & 24,8 \\ 27,2 & 26,4\end{array}$

Auf dem anterioposterioren $\mathrm{R} \ddot{\mathrm{n}} \mathrm{tg}$ e n bilde ist der Akromialgelenkspalt zwar gedeckt, indes kann man die beiden sich deckenden Gelenkenden auseinanderhalten und keine Unregelmäßigkeiten ihrer Oberfläche sehen.

Die Diagnose wird trotz fehlenden Röntgenbefundes wie auch im. Fall 2 auf eine traumatische Schädigung und Ent. z ündung des Akromialgelenks gestellt, da der örtliche Druckschmerz, die auf das Gelenk beschränkte Krepitation und vor allem die sehr charakteristische Bewegungsstörung bei völlig freiem Schultergelenk darauf hinweisen. Um die Diagnose zu stützen und vor allem die Unterscheidung von einer Bursitis subacromialis sicher zu stellen, wird eine Novokaininjektion ins Gelenk ausgeführt, und zwar, da eine solche von vorn nicht den gewünschten Erfolg bringt, auch noch eine 2. und 3. Injektion von oben und hinten, wobei man jedesmal deutlich in den Gelenkspalt kommt. $\mathrm{Nach}$ diesen drei Injektionen weniger Kubikzentimeter verschwinden die Beschwerden vollkommen, und es werden alle Bewegungen, auch Schleuderbewegungen frei.

\section{Zusammenfassung:}

Ein Jahr lang bestehen sofort nach einer direkten Quetschung der Schulter eingetretene Störungen im rechten Akromialgelenk, die durch mediko-mechanische Behandlung nur unvollkommen gebessert werden. Die Diagnose wird, abgesehen von dem örtlichen Druckschmerz und der Krepitation, vor allem auf die bei Bewegung der Achsel nach oben, vorn und hinten eintretenden Störungen begründet und durch eine alle Beschwerden beseitigende Novokaininjektion bestätigt.

Fall 4. K. R., 4ojähriger Asphaltstampfer.

Ist Anfang April r.9I3 mit der hinteren AuBenseite der linken Schult er beim vergeblichen Ziehen an einem Wagenschutz durch plötzliches Nachgeben desselben vom Wagen herunter und auf die Bordkante des Trottoirs a ufgeschlagen. Hat zunächst geringfügige Beschwerden gehabt, und deswegen mit Einreibungen weitergearbeitet. Erst nach $3 \mathrm{Wochen,} \mathrm{im} \mathrm{Mai}$ haben sich an der Schulter stärkere Schmerzen eingestellt, 
die an der vorderen Kontur beginnen und über die Schulterhöhe nach hinten ziehen. Es sei manchmal ein stechender Schmerz ganz plötzlich eingetreten, wie wenn man mit einer Nadel in den Knochen hinein. gestochen habe. Patient zeigt dabei auf den oberen äußeren Abschnitt des Deltamuskels in der Richtung nach dem Humerusschaft zu. Der Schmerz sei über die Außenseite des Arms bis zum Ellenbogen hinüber gezogen. Er habe ferner beim Heben des Stampfers, wobei der Arm in der Richtung von vorn unten nach oben außen gehoben wird, oben in der Schulter ein plötzliches „Knupsen", wie wenn ein Knochen überschnappt, bemerkt. Im Mai 1913 hat er 14 Tage ausgesetzt, dann nicht mehr Asphalt gestampft, sondern Holzpflaster gesetzt. Seit er Mitte Februar I9I4 wieder als Asphaltstampfer angefangen hat, treten die Beschwerden in erhöhtem Maße auf.

Untersuchung am 6. III. I9I4: Das linke Akromialgelenk ist deutlich geschwollen. Sowohl eine stärkere Ausfüllung der Grube an der Außenseite des Schlüsselbeins bemerkbar, als auch prallere Resistenz und größerer Durchmesser beim Betasten des Gelenks von vorn nach hinten. Das Gelenk ist ausgesprochen druckempfindlich. Außerdem gibt $K$. bei Druck auf die äußere Deltamuskelpartie Schmerz an, der bei sämtlichen Bewegungen bestehen bleibt, ohne da $B$ hier Krepitation oder Verdickung nachweisbar ist. Bei steilster Hebung der Achsel Schmerz auf der Schulterhöhe bzw. dahinter, beim Senken kurz vor Erreichung der Ruhelage Krepitation am Akromialgelenk. Beim Vorwärtsschieben der linken $\mathrm{Schulter} \mathrm{Schmerz}$ etwas unterhalb des Akromions bis auf die Höhe des Gelenks ziehend. Patient hat hierbei das Gefühl, als wennesinder (iegend des Akromialgelenksspannte, ,als wenn ihn dort jemand halten wollte". Ausgiebige Rückwärtsführung der Achsel verursacht ebenfalls Schmerz. Wesentlicher Unterschied zwischen rechts und links bei der Abduktion, der linke Arm kann nur bis 105 Grad erhoben werden, der rechte nahezu senkrecht. Links fühlt mankein Krachen, rechts ist solches bemerkbar. Bei der vertikalen Elevation über vorn im letzten Moment leises Schnappen im Akromialgelenk, das schmerzhaft sein soll. Erhebung bis 135 Grad möglich, rechts bis 82 Grad. Auf beiden Seiten tritt bei der extremen Bewegung Knacken ein. Links schmerzhaft, rechts ohne Schmerzen. Eine wesentliche Atrophie ist am kranken Arm nicht vorhanden. Der linke Arm ist sogar

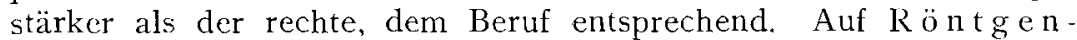
bildern kein deutlicher Unterschied zwischen rechts und links. Beide Clavicularenden zeigen konkave Kontur.

Diagnose: Synovitis acromio-clavicularis traumatica recidiva. Eine Novokaininjektion bestätigt sie, da dic Beschwerden durch sie sofort beseitigt werden, und die Be- 
Die Arthritis acromio-clavicularis als wichtiges Glied in der Pathologie usw. 6I 3

wegungen fast frei, soweit nicht die Spannung im Gelenk ein Hindernis darstellt.

Massage tut dem Verletzten gut, Ubungen haben aber bis zum I5. III. noch keinen wesentlichen Erfolg gebracht.

\section{Zusammenfassung:}

Durch Kontusion ausgelöste, drei Wochen später stärkere Beschwerden verursachende Entzündung im linken Akromialgelenk, die nach einem Jahr bei verstärkter Beanspruchung des Gelenks rezidiviert, jetzt mit deutlichem Erguß ins Gelenk einhergeht, schmerzhafter Behinderung der vertikalen Elevation sowie der Achselverschiebungen. Durch den Erguß ins Gelenk wird die Krepitation zum Teil aufgehoben. Beseitigung der Beschwerden durch Novokaininjektion ins Gelenk für mehrere Stunden.

Fal1 5. K. H., 6ojähriger Bauarbeiter.

Stürzte am I7. XII. I9I3 rittlings auf einen Versteifungsbalken und zu gleicher Zeit auf die $\mathrm{H} \ddot{a} \mathrm{nde}$, von denen die linke hart aufstauchte, mußte nach 2 Stunden vor allem wegen Schmerzen im Unterleib die Arbeit aussetzen, hatte aber gleichzeitig bereits Schmerzen in der Schulter. Wurde vom 17. XII. bis 3I. I. I9I4 wegen HarnröhrenzerreiBung mit Urethrotomia ext. und Sectio alta im Krankenhaus stationär behandelt.

Untersuchung am 3. III. I914: Klagt über lästige Schmerzen in der linken Schulter, von denen er vor dem Unfall nichts bemerkt hat, obgleich er stets als Bauarbeiter schwer hat tragen müssen. Die Schmerzen wurden oben in der Schulter lokalisiert, von wo sie über die äußere Seite des Arms nach dem Ellenbogen ziehen. Sie sollen vor allem beim seitlichen Erheben des Arms wie beim Rückwärtsbewegen und gleichzeitigem Einwärtsdrehen auftreten. Er wird nachts gestört, da er nicht auf der kranken Seite liegen kann, ohne daß Schmerzen eintreten.

B ef u n d: In der Gegend des linken Akromialgelenks sind die Konturen deutlich verstrichen und die Resistenz derber als auf der rechten Seite. Die Einsenkung am Außenrande des Schlüsselbeinendes fehlt, statt dessen hier eine prallere Schwellung, die in frontaler Richtung Fluktuation gibt. Am Akromialgelenk selber umschriebener, lebhafter Druckschmerz.

A chselheben wird links und rechts gleichmäßig ausgefuhrt, ist aber links ausgesprochen $\mathrm{s} \mathrm{chmerzhaft}$. Beim Herablassen der Schulter vor Erreichung der Ausgangsstellung Krachen im Akromialgelenk. Beim Vor- und Rückwärtsheben reichliche Krepitation. Schmerzbei a usgiebigen Rückwärtsbewegungender A chsel. Heben des Arms über die Horizontale ebenfalls schmerz- 
haft. Am rechten Akromialgelenk ebenfalls Reiben, aber keine Schmerzen. Die Abduktion des Arms führt links bis Ioo Grad, rechts bis I50 Grad. Beim Überschreiten der Horizontale links Krepitation, rechts nicht. Vorwärtshebung links bis I20 Grad, rechts bis 145 Grad. Bei höherer Elevation tritt dann links Schmerz oben in der Schulter ein. Rückwärtshebung des linken Arms bis $38 \mathrm{Grad}$ (rechts bis 60 Grad) möglich. Dabei leises Knirschen im linken Akromialgelenk. Am linken Arm und Schulter ist keine Abmagerung zu bemerken.

Umfangsmaße:

Am Ansatz des Deltamuskels

Oberarm II cm über dem Speichenköpfchen

Vorderarm $2 \mathrm{~cm}$ unter demselben

$\begin{array}{cc}\text { rechts: } & \text { links: } \\ 30,0 & 30,8 \\ 27,0 & 26,3 \\ 26,0 & 25,8\end{array}$

rechts: links: $27,0 \quad 26,3$ 25,8

Am rechten $\mathrm{Kniegelenk}$ besteht reichlichere $\mathrm{Krepita-}$ tion als links, ohne daß sonstige Störungen deutlich sind, insbesondere keine Kapselverdickung. $K$. will aber gelegentlich $\mathrm{Schmerz}$ in diesem Gelenk empfinden. Auf vergleichenden Röntgenbildern beider Kniegelenke von vorn und seitlich deutliche deformierende Veränderungen nicht zu sehen, nur die Spitzen der Tubercula intercondyloidea rechts etwas in die Länge gezogen. Die Röntgenuntersuchung der Akromialgelenke fällt negativ aus. Beiderseits normale Gelenkspalte. Auch die Humeroskapulargelenke sind vollkommen normal.

\section{$Z$ usammenfassung:}

Infolge Falles auf die Hand schmerzhafte Affektion in der linken Schulter, die zunächst wegen anderer Affektion nicht beobachtet wird, aber zunehmende Beschwerden macht. Behinderung der vertikalen Elevation und der Achselbewegung nach oben und hinten. Die örtlichen Veränderungen sprechen für eine akute Arthritis des Akromialgelenks mit Anschwellung der Bursa subcutanea acromialis. Vielleicht ist diese infolge Lastentragens auf der Schulter schon vor der Verletzung stärker ausgebildet gewesen.

\section{Chronische traumatische Arthritis}

a) bei nachweislicher Fraktur am akromialen Ende des Schlüsselbeins.

F all 6. M. G., 27jähriger Bauarbeiter.

Am I. XII. rgi 3 fiel M. a uf die linke Schulter in ein Erdloch, konnte hinterher den Arm schlecht heben, hat a ber noch leichtere Arbeit verrichtet, und erst am nächsten Tag 
einen Arzt aufgesucht, und Einreibungen erhalten. Die Schmerzen in der Schulter haben lange Zeit bestanden, ebenso eine gewisse Steifigkeit. Die Schmerzen sollten vor allem dann auftreten, wenn er den linken Arm eine Zeitlang aufgelegt hat, ferner nachts, wenn er auf der Seite gelegen hat. Er ist schon im Jahre 1909 beim Militär auf die linke Schulter gefallen, ist aber nach I4 Tagen beschwerdefrei gewesen. Im Jahre 1906 hat er gelegentlich Säcke auf der linken Schulter getragen. Er kommt in die Poliklinik, weil er fürchtet, daß etwas , kaput" sei.

Spontane Schmerzen in der Gegend des Akromialgelenks beginnend und von da bis uber die Außenseite des Deltamuskels bis etwa zu seinem Ansatz hinziehend. Wenn er den Arm heben will, läßt manchmal die Kraft plötzlich nach, so daß er ihn fallen lassen muB.

Erste Untersuchung am i6. I. I9I4: Die Gegend des linken Akromialgelenks springt deutlich sichtbar vor. Knochenharte, besonders nach hinten zu gerichtete Verdickung des Clavicularendes auf fast die doppelte Breite der rechten Seite. Der Gelenkspalt des Akromialgelenks, der deutlich fühlbar, ist druckempfindlich. Weichteilschwellungen fehlen. Die Schultern zeigen im ubrigen gleiche Konturen, kein Druckschmerz am Schultergelenk. Keine Atrophie. Bei Rotationsbewegungen Krepitation am Akromialgelenk. Beim Erheben der Achsel dreht sich der untere Winkel des Schulterblatts: stärker nach außen als auf der gesunden Seite. Fixiert man ihn, so kann die linke Achsel 3-4 cm weniger hoch erhoben werden als die rechte. Die vertikale seitliche Erhebung ist links bis zu einem Winkel von I30 Grad ausführbar. Bei den Vorwärts- und Rückwärtsbewegungen kein Krachen im Gelenk.

Auf dem Röntgenbilde der linken Seite deckt sich der Gelenkspalt durch unregelmäßige Auflagerungen an beiden Knochenenden zu. Sein Schatten ist teils etwas dichter, teils locker blasig gezeichnet. Besonders ist das Clavicularende stark spongiös. Oberhalb des Spalts findet man kleine splitterartige Flecken (vgl. Fig. 2). Auf der rechten Seite liegen durchaus normale Verhältnisse vor.

Diagnose: Kontusion (Fraktur?) des akromialen Endes der Clavicula und des Gelenks. Teilweise Versteifung des Gelenks. Die bis zum 7. III. ausgeführte Behandlung mit Heißluft und Massage mildert die Schmerzen und läßt die Beweglichkeit des Arms etwas freier werden. Objektiv keine wesentliche Änderung. Nur die Krepitation bei den rotierenden Bewegungen ist weniger deutlich.

\section{Zusammenfassung:}

Nach direkter Quetschung allmählich zunehmender Schmerz und Steifigkeit der linken Schulter mit gelegentlich plötzlichem 
Versagen der Kraft beim Anheben des Arms. Mitbewegung des Schulterblatts beim Achselheben spricht für Versteifung des Akromialgelenks, die starke Auftreibung des Claviculaendes für eine vorangegangene verheilte Fraktur, die auf den Röntgenbildern nicht deutlich zu erkennen ist.

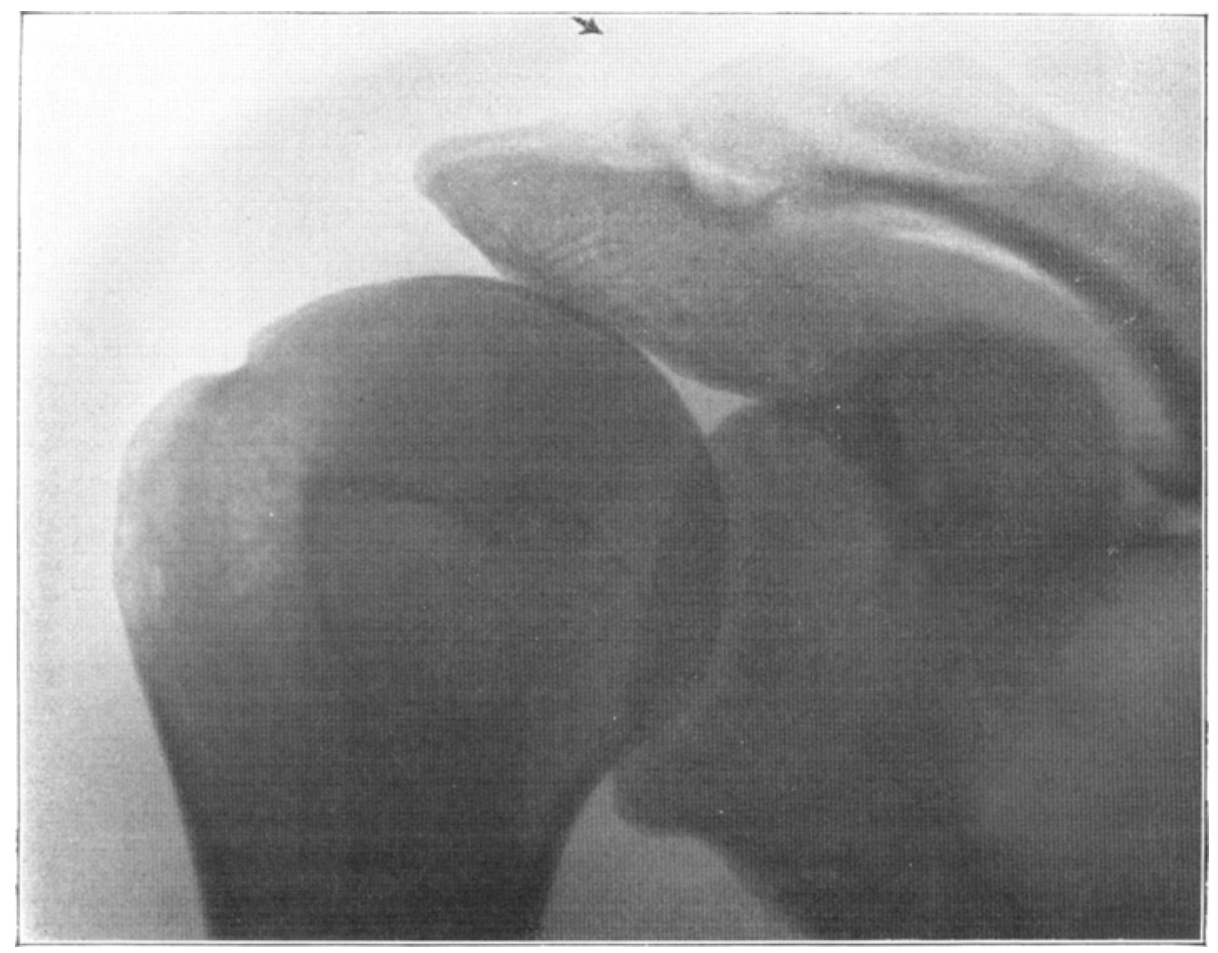

Fig. 2. (Fall 6, S. 615).

Fall 7. C. M., 36jähriger Arbeiter.

Kam am I3. XII. IgI3 zu Fall dadurch, daß seine Vordermänner einen von ihm am anderen Ende mit getragenen Balken fallen ließen. Bewußtlos. Bluten aus Nase und Mund. Geringe Pulsbeschleunigung und Temperatursteigerung. Bißwunde an der Zunge. Ohrabschürfung und Bluterguß im Kieferwinkel. Fünfmarkstück große Hautabschürfung hinten an der rechten Schulter. Rechtseitiger typischer Knöchelbruch. Behandlung im Krankenhaus vom 13. XII. I9I3 bis 3. II. IgI4.

$\mathrm{Nachuntersuchung}$ für die Berufsgenossenschaft am 
I0. III. I9I4, soweit sie die Schulteraffektion betrifft: Verdickung des akromialen Endes der rechten Clavicula. Clavicula von vorn nach hinten auf fast das Doppelte verbreitert. Das Ende selber sowie das Akromialgelenk ist druckschmerzhaft. Das Schultergelenk ist frei und keine Muskelatrophiebemerkbar. Beim Schieben der Schulter nach vorn hebt sich das Schlüsselbeinende etwas nach hinten heraus, während bei der Achselverschiebung nach hinten seine Prominenz einigermaßen verschwindet. Der rechte Arm kann seitlich bis I 40 Grad erhoben werden, der linke bis I70 Grad, wobei aber der Verletzte das Gefühl hat, als wenn in der Schulter etwas "gegendrückte". Beim Heben nach vorn springt das Schlüsselbein-

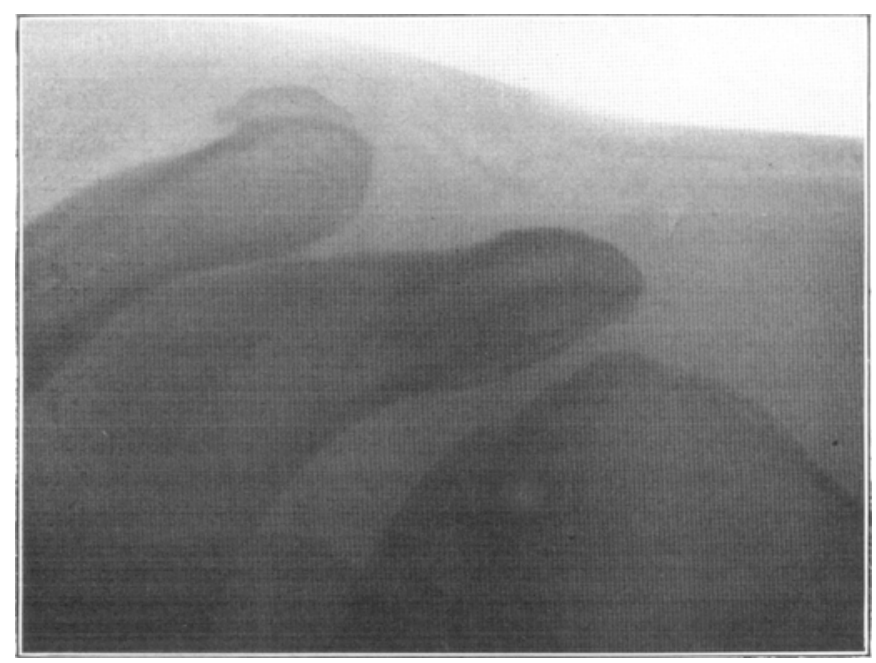

Fig. 3.

ende wieder hinten abnorm vor. Die Hebung nach vorn führt bis I 40 Grad, links bis 150 Grad, die nach hinten nur bis 35 Grad, links bis 55 Grad. Bei ausgiebigen Pendelbewegungen lebhafter Schmerz und Krachen im Schultergelenk. Die Schulterblätter verhalten sich bei allen Bewegungen gleichmäßig. Rotationsbewegungen sind nicht beschränkt, an der linken Schulter bei ausgiebigen Bewegungen ebenfalls reichliche Krepitation, aber kein Schmerz.

Die Diagnose wird auf Fraktur des akromialen Endes der Clavicula mitentzündlicher Beteiligung des Akromialgelenks gestellt.

Das Röntgenbild bestätigt die Frakturdiagnose, indem man auf der oberen Kontur des Clavicularendes ein kalottenförmiges Fragment liegen findet (vgl. Fig. 3). 


\section{Zusammenfassung:}

Die infolge wahrscheinlich direkten Traumas entstandene Fraktur des akromialen Endes der Clavicula verursacht noch nach einem Vierteljahr Beschwerden, wie sie den Entzündungen des Akromialgelenks eigen sind. Das Verhalten des verdickten Claviculaendes bei dem Verschieben der Achsel von vorn nach hinten läßt deutlich die auf $\mathrm{S} .602$ beschriebenen Bewegungen im Akromialgelenk zum Vorschein kommen. Die Krepitation auf der gesunden linken Seite hängt vielleicht mit einer vor 4 Jahren erlittenen Schulterverrenkung zusammen.

\section{b) Ohne erkennbare Fraktur.}

F a 11 8. K. P., 38jähriger Färber.

Infolge Ausrutschens schlug K. am 3. V. 1905 mit dem rechten Schlüsselbein, wie er selber berichtet, gegen die obere Kante eines Schleuderkessels; der dabei eintretende Schmerz erregte Übelkeit. Indes ging $\mathrm{K}$. erst am 29. V. zum Arzt wegen zunehmender Schmerzen und Bewegungsstörung. Es wurde damals ein Schlüsselbeinbruch am Brustende angenommen. Die Abduktion besonders erschwert. K. brauchte die Arbeit nicht zu unterbrechen. In den folgenden Jahren spielt in den ärztlichen Gutachten immer nur der bedeutendere Vorsprung am sternalen Endedes Schlüs. selbeins und der dadurch bedingte Schmerz eine Rolle. Im August 1906 soll die Rente aufgehoben werden, wird aber durch Schiedsgericht wieder hergestellt. I9I I wird vom Sachverständigen eine $c h$ ronische Entzündung der Schulter angenommen wegen reibender und knackender Geräusche dort. Eher Verschlimmerung als Besserung. Im Mai I9I 3 wird $\mathrm{K}$. dem Verfasser zur Untersuchung zugewiesen.

Erste Untersuchung: Man sieht eine beträchtliche Verdickung beider Enden des Schlüsselbeins. Die Verdickung am Brustbeinende ist bedeutender, aber nicht mehr druckempfindlich. Außen laut hörbares Knacken bei Bewegungen. Bei ausgiebigeren passiven Bewegungen unangenehm empfindlich. Im Schultergelenk selber sind keine Geräusche wahrnehmbar. Geringfügige Atrophie der Schultermuskeln. Der Arm ist nicht abgemagert. Außer der Fraktur am sternalen Ende wird mit Wahrscheinlichkeit eine Verletzung am akromialen Ende angenommen, und aus diesem Grunde eine Hebung der Erwerbsfähigkeit abgelehnt.

$\mathrm{Nachuntersuchung}$ am 4. III. I9I4: Beim Achselheben fühlt man im rechten Sternalgelenk Schnappen, wobei das Clavicularende nach vorn und oben springt. Das stark verdickte Akromialende 
verschwindet dabei in seinem Gelenk, so daß es kaum noch vorspringt. Während das Vorschieben der Achsel beschwerdefrei und beiderseits gleich ausgeführt wird, nimmt man bei der $R \ddot{u} c k$. wärtsbewegung starke Krepitation im Akromialgelenk wahr, und der Verletzte empfindet Schmerz en. Beim seitlichen Erheben des Oberarms, das bis 140 Grad möglich ist, Krepitation im. Akromialgelenk deutlich. Der linke wird bis 180 Grad gehoben, auch hier bemerkt man oberhalb der Horizontalen Krepitation. Bei Bewegung nach vorn, die bis 140 Grad lührt, im Beginn Krepitation, bei derjenigen nach hinten, dje bis 50 Grad möglich ist, im Moment der Rückkehr zur Ausgangsstellung.

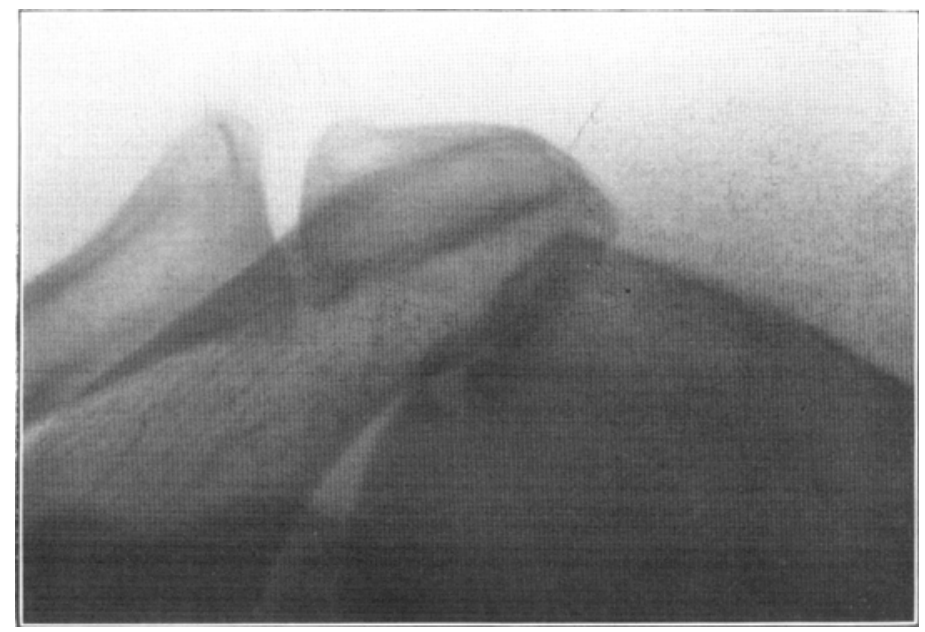

Fig. 4.

(Bei allen diesen Bewegungen im Sternalgelenk keine Schmerzen und kein Krachen.) Der linke Arm kann nach vorn bis 62 Grad, hinten bis 65 Grad ohne Krachen und Schmerz erhoben werden. Bei den Rotationsbewegungen fühlt man unterhalb des Akromions in der Umgebung des Humeruskopfes feines Knirschen durch den Deltoideus durch. Keine Abmagerung der Schulterblattmuskeln mehr.

Die Röntgenuntersuchung stellt fest, daß das Sternal. ende der Clavicula wesentlich vergrößert, poröser ist, und seine untere Kontur einen kieinen Osteophyten trägt. Das äußere Ende zeigt bei der anteroposterioren Aufnahme nur etwas wulstig ver. dickte, dorsale Ränder der beiden Knochen, sowie einen abnorm klaffenden Spalt (vgl. Fig. 4).

Diagnose: Fraktur des sternalen Endes der 
rechten Clavicula sowie chronische Arthritis acromio-clavicularis mit Hypertrophie des akromialen Endes der Clavicula.

\section{Zusammenfassung:}

Durch eine das Schlüsselbein direkt treffende Gewalt kommt es zur Fraktur des sternalen Clavicularendes und zur Distorsion des distalen Endes am selben Knochen. Infolgedessen stellt sich im Laufe des Jahres hier eine chronische Gelenkentzündung ein, die zunehmende, nicht sehr heftige Beschwerden verursacht. Die Affektion des Gelenks wird klinisch sichergestellt durch die örtliche Empfindlichkeit, die Verdickung des akromialen Clavicularendes, die charakteristische bei Rückwärtsbewegung der Achsel eintretende Schmerzhaftigkeit und Krepitation, sowie auch durch die Röntgenuntersuchung, die einen abnorm weiten Gelenkspalt und aufgeworfene Ränder der beiden Knochen zeigt.

Fall 9. H. F., 56jähriger Buchdrucker.

Ficl Mitte Februar 1913 in ein Papierloch, wobei er mit dem rechten Ellenbogen aufschlug und dadurch vor dem Tieferstïrzen bewahrt wurde. Sofort heftige Schmerzen in der rechten Schulter. Trat sofort in ärztliche Behandlung, kam am 24. II. in die Poliklinik, nachdem er zweimal wegen Gesundschreibung durch den Vertrauensarzt der Kasse vergeblich versucht hatte zu arbeiten.

Bei der ersten Untersuchung finden sich ausgesprochene Druckschmerzen am Akromialgelenk, auf dieses Gelenk zu lokalisierende Krepitation und Schmerzen bei allen ausgiebigen Bewegungen, auch schon unterhalb der Horizontalen. Schultergelenk offenbar frei. Zunächst Behandlung mit Massage und Übungen, ohne daß Besserung eintritt. Röntgenuntersuchung zeigt dann deutlich Veränderung des Acromioclaviculargelenks; während am linken eine glatte, rundliche Kontur des clavicularen Endes und ebenfalls geradlinige Begrenzung des Akromions sichtbar ist, ist dieser rechts durch unregelmäßige, bläschenartige Auflagerungen am Akromion, sowie auch durch das zackige, ebenfalls in seiner Struktur blasig gezeichnete Clavicularende verdeckt (vgl. Fig. 5).

Wegen der Vergeblichkeit der bisherigen Behandlung und der recht starken Beschwerden wird am 6. III. die Resektion des Gelenks ausgeführt: von einem Schnitt in der Richtung des Schlüsselbeins wird nach Ablösung des Deltamuskelansatzes das Gelenk keilförmig ausgemeißelt. Die Knorpelflächen sind uneben rauh, gelblich; nirgendwo mehr guterhaltener Knorpel zu sehen. Schluß- durch Fascien- und Hautnaht.

Zunächst einige Tage Fixation des Arms mit Desaultschem Ver- 
Die Arthritis acromio-clavicularis als wichtiges Glied in der Pathologie usw. 62 I

band. Nach 3-4 Tagen lassen die zunächst lebhaften Schmerzen nach. Unter anschließender Massage und Übungen sichtliche Fortschritte, so daß H. bald seine große Zufriedenheit über die Beseitigung der Schmerzen äußert. I4. IV. Wiederaufnahme der Arbeit $\mathrm{Nachuntersuchung}$ am 27. I. 19I4: Die $9^{1 / 2} \mathrm{~cm}$ lange Narbe an der vorderen Kontur des alten Akromialgelenks ist ganz

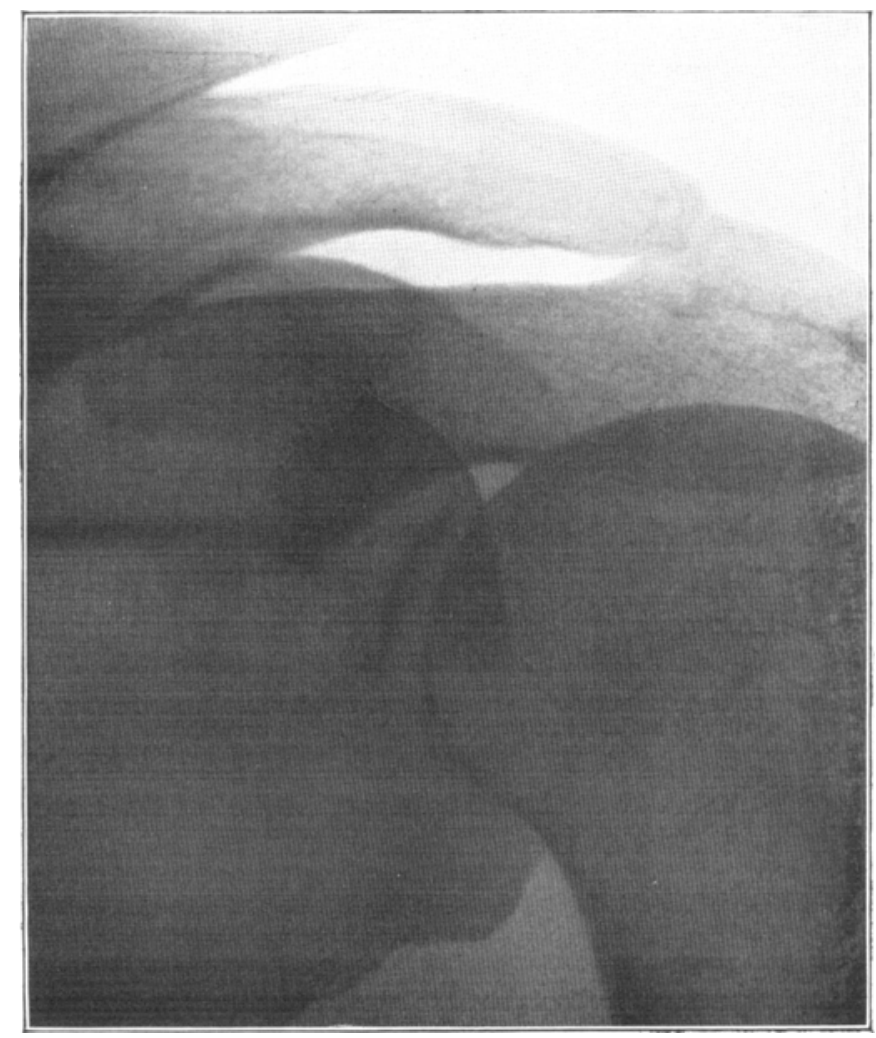

Fig. 5 .

reizlos, auf der Unterlage verschieblich und unempfindlich. Das Reseiktionsende des Schlüsselbeins springt etwas stärker vor, es hat gute rundliche Form, ist unempfindlich gegen Druck und zeigt dieselbe federnde Beweglichkeit wie das linke Akromialende. In dem durch die Resektion gesetzten Spalt fühlt man deutlich eine meniskus. artige Einlage, die ebenfalls federt. H. kann seine Arbeit recht gut verrichten, hat die früheren Beschwerden nicht wieder gehabt, nur bei anhaltendem schweren Heben gelegentlich noch Schmerzen an 
der Operationsstelle. Der rechte Arm kann bis zum Winkel von I25 Grad bis zur Vertikalen erhoben werden: die Bewegungen sind im übrigen auf beiden Seiten symmetrisch ausführbar. Bei den Rotationsbewegungen des abduzierten Arms fühlt man auf der linken gesunden Seite grobes Krachen, das rechts fehlt. Die fortlaufenden Röntgenuntersuchungen zeigen eine allmählich zunehmende Schließung des zunächst keilförmigen Defekts dadurch, daß sich das Clavicularende zuspitzt und eine vom Akromialende ausgehende Prominenz sich ihm nähert (Fig. 6). Man erkennt indes besonders

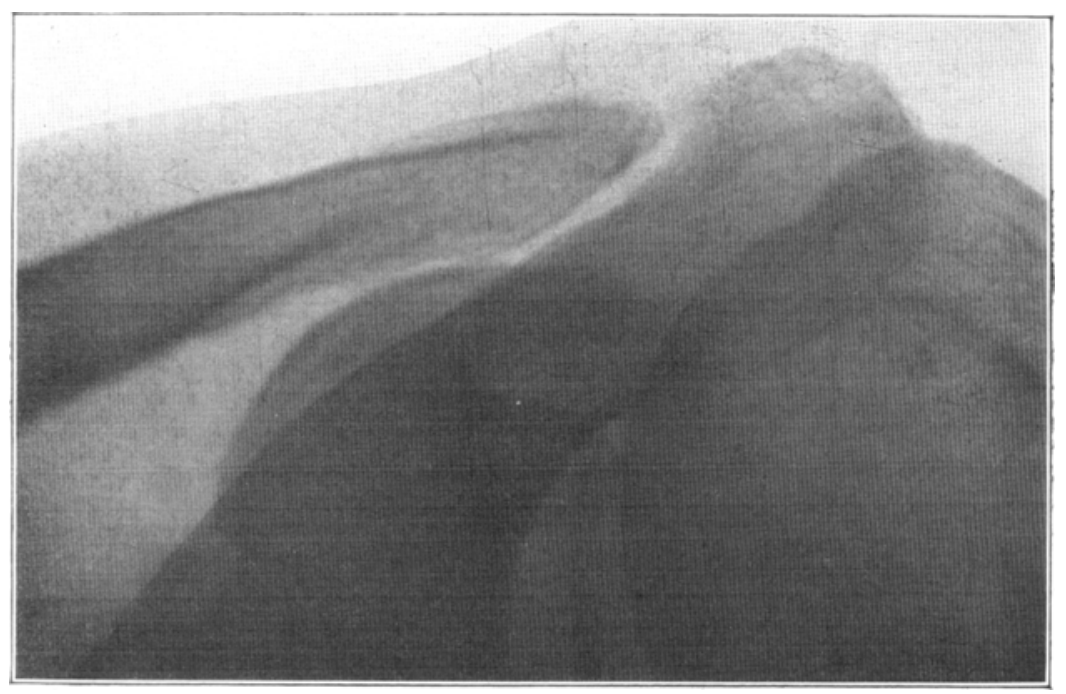

Fig. 6.

auf der axialen Aufnahme (Fig. 7), daß der Gelenkspalt nicht durchweg so schmal ist, wie auf den ersten Blick das Bild von vorn denken lassen möchte, da $\beta$ vielmehr nur an einem Ende kleine rundliche abgelöste Knochenschatten sich zwischen die beiden Gelenkenden legen und den Spalt verschmälern. Tatsächlich hat der Gelenkspalt noch eine ganz ansehnliche Breite.

\section{Zusammenfassung:}

Im Anschluß an ein indirektes Trauma treten heftige Schmerzen mit Bewegungsstörungen der rechten Schulter ein. Nach I 4 Tagen (erste Untersuchung) ausgesprochener Druckschmerz und Krepitation am Akromialgelenk nachweisbar. Vergebliche Behandlung unter immer wieder heftigen Schmerzen mit: 
Massage und Übungen. . Der Röntgenbefund bestätigt die klinisch gestellte Diagnose auf Arthritis acromioclavicularis nach Trauma, da der Gelenkspalt verschwunden und die beiden Gelenkenden unregelmäßig und porös erscheinen. Die Resektion des Gelenks beseitigt in einem Monat die Beschwerden, macht den Mann arbeitsfähig. Die Nachuntersuchung nach io Monaten ergibt gute Funktionen der er-

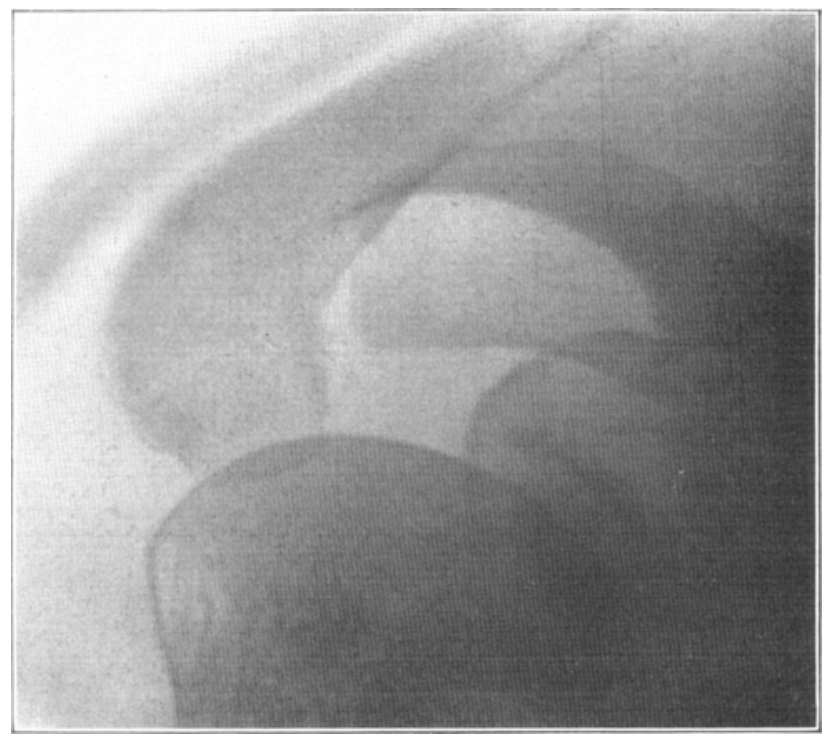

Fig. 7.

krankten Schulter, die nur bei anhaltendem schwerem Heben gelegentlich schmerzhaft wird. Nach dem klinischen Befund hat sich eine anscheinend mit Meniscus versehene Nearthrose gebildet. Röntgenologisch hat sich der Defekt durch Apposition an den beiden Gelenkenden verkleinert.

Fall ro. B. P., 67jährige Witwe.

Sprang im Januar I9I2 aus einem Wagen auf ein Brett; da es kippte, stürzte sie auf die rechte $\mathrm{H}$ and. Seitdem Schmerzen im rechten Handgelenk und in der rechten Schulter.

Untersuchung am 2. III. 19I4: (Abgesehen von einer typischen, schlecht reponierten $\mathrm{R}$ adiusfraktur an der rechten Hand.) Schmerz am Ansatz des rechten Deltamuskels, vor allem 
beim seitlichen Erheben und Einwärtsdrehen des abduzierten Arms. Geringfügige Verdickung am Außenende der Clavicula zu erkennen. Lruckschmerz am Akromialgelenk sowie an der vorderen Kontur der beiden benachbarten Knochen. Schultergelenk nirgendwo empfindlich. Beim Vorwärtsschieben der rechten Achsel, das entschieden schwieriger ist als links, fühlt und hört man grobes Krachen in der Gegend des Akromialgelenks, ebenso bei der Abduktion im Moment der Kontraktion des Deltamuskels. Das Erheben bis zur Horizontale ist bereits erschwert. Vor- und Rückwärtsheben des Armes ist leicht ausführbar. Bei ausgiebigeren passiven Bewegungen in diesem Sinne aber auch Schmerzen und Krepitation. Beistarker passiver Rotation nach a u Ben erhebliche Krepitation um den Humerus herum f üh 1 bar.

Diag nose: Arthritis acromialis traumatica, wahrscheinlich mit Beteiligung des Spatium subdeltoideum. Um nach Möglichkeit die Diagnose zu sichern, Vornahme einer In jekt i o n von Novoka in. Adrenalin in das Spatium subdeltoideum direkt unterhalb des Akromion. Man glaubt danach zu fühlen, daß dic Krepitation bei Rotation geringer geworden ist. Jedenfalls hat auch der Schmerz bereits etwas nachgelassen. Indes wird derselbe crst vollständig beseitigt nach einer in geeignetem Abstande vorgenommenen Einspritzung ins Akromialgelenk. Jetzt ist erst die Bewegung des Armes vollkommen frei und das grobe Knacken bei Beginn der Abduktion fällt weg.

Auf dem anteroposterioren Röntgenbilde (Fig. 8) sieht man an der Spitze des Akromions einen durch einen gewellten Spalt sich absetzenden kleinen Knochen mit ziemlich glatter Oberfläche, der sich auch bei der axillaren A uf nahme (Fig. 9) ausprägt. Hier erkennt man aber deutlich sowohl auf der Akromialspitze, wie an dem Schaltknochen spitzig-zackige Ostcophyten. Links ganz normale Verhältnisse.

\section{Zusammenfassung:}

Die Diagnose einer chronischen Arthritis acromialis im Anschluß an ein indirektes Trauma konnte klinisch auf örtlichem Druckschmerz, geringer Verdickung des Gelenks sowie Behinderung der Vorwärtsbewegung der Schulter mit großer Wahrscheinlichkeit begründet werden. Die Röntgen untersuchung stellt eine Art „Schaltknochen“ fest, vielleicht ein Os acromiale terminale, konnte aber durch axillare Aufnahme pathologische Verhältnisse ermitteln, die als chronisch deformierende anzusehen sind. Wegen der diffusen Krepitation um das obere Humerusende bei Rotationsbewegungen 
Die Arthritis acromio-clavicularis als wichtiges Glied in der Pathologie usw. 625

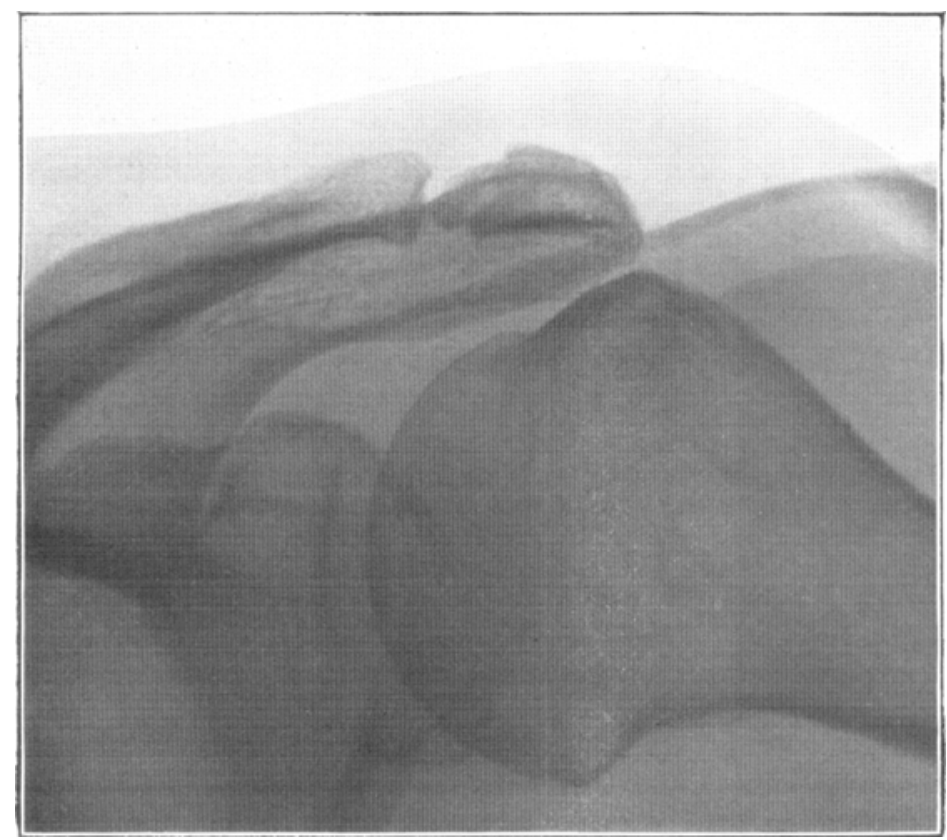

Fig. 8.

mußte außerdem eine Erkrankung des Spatium subdeltoideum angenommen werden. Beide Annahmen bestätigten sich durch

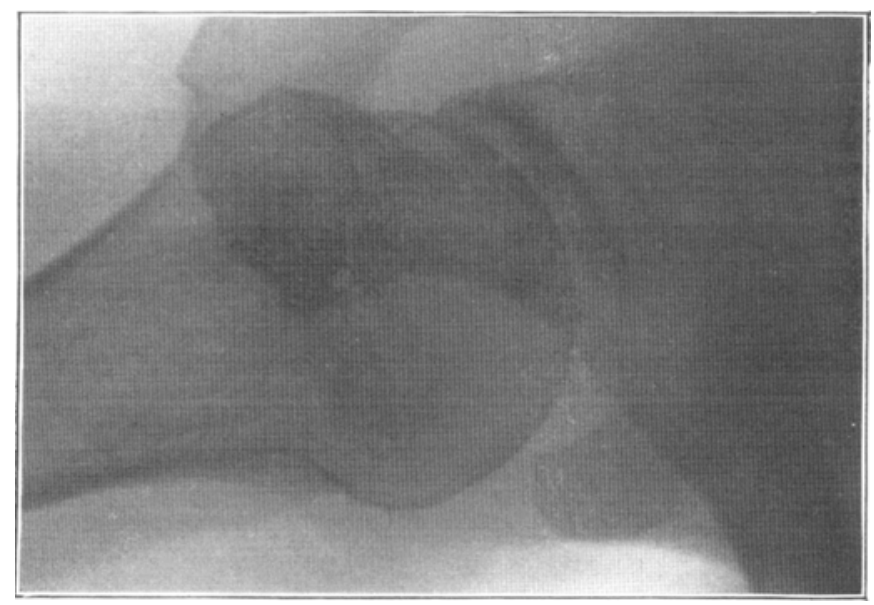

Fig. 9 . 
die Injektion des Anästhetikums, indem die auf jeden Abschnitt zurückzuführenden Beschwerden sukzessive durch die Injektion beseitigt wurden. Leider war die Frau auf Reisen und wollte sich auf die vorgeschlagene Resektion nicht einlassen.

\section{Arthritis chronica deformans}

a) nach Trauma (sekundär).

Fall II. R. W., 57jähriger Arbeiter.

Rutschte am 27. VIII. I908 von einem Balken ab, wollte sich im Fallen mit der rechten Hand an einem anderen halten, wobei der $\mathrm{rechte}$ Arm stark hochgerissen wurde, wobei ein $\mathrm{Knacken}$ in der Schulter auftrat, so daß er loslassen mußte und dann noch I $1 / 2$ Stock tief auf Rücken und Kopf fiel.

Wurde vom 2 I. VII. bis I I. X. 19I 3 wegen Folgen jenes Falles mit Massage und Übungen behandelt. Es trat eine gewisse Besserung ein.

Untersuchung am 6. II. I9I4: R. bezieht wegen der Folgen des Unfalls vom August 1908 an der rechten Schulter noch eine Rente von 15 Proz. Er ist jetzt Reisender und kann seiner Beschäftigung nachgehen, kommt nicht wegen der Schulter, sondern wegen Plattfußbeschwerden in die Poliklinik.

Das akromiale Ende des Schlüsselbeins rechts springt bedeutend stärker vor als das des linken, vorn sowohl wie nach oben. Sagittaler Durchmesser beträgt rechts $5 \mathrm{~cm}$, links $4 \mathrm{~cm}$. Außen rechts cine tiefere Delle als links. Das Clavicularende ist passiv von vorn nach hinten besser verschieblich als links. Schulterblatt steht rechts $2 \mathrm{~cm}$ tiefer. Bei der Abduktion bewegt sich die Spitze beiderseits eben vor der Erreichung der Horizontalen nach außen, legt bis zur Horizontalen eine Distanz von $2 \mathrm{~cm}$ zurück, bis zur Vertikalen links von $12 \mathrm{~cm}$. Rechts wird der Arm nur bis 105 Grad erhoben; bei maximaler Erhebung steht der Angulus inf. scapulae rechts und links gleich. Vor Erreichung der Horizontalen jammert der —durch Renteninteresse und Fettsucht mit Arteriosklerose recht wehleidige -- Mann sehr über Schmerz an den vorderen Abschnitten des Deltoideus. Schwellung hier nicht nachweisbar, vielleicht Muskelbündel etwas derber als links. Schmerz nimmt bei passiven Vertikalerhebungen über den angegebenen Grad erheblich zu. Vorwärtserhebung ist rechts ebenfalls bis I05 Grad, links bis 145 Grad möglich. Starke Behinderung der Armbewegung rückwärts, die nur um I5 oder 20 Grad möglich ist, links bis 55 Grad. Dabei sofort ziemlich lebhafte Schmerzen auf der Schulterhöhe.

Röntgenuntersuch ang: Links geradlinig begrenzter Gelenkspalt von normaler Breite. Nicht ganz absolut glatte Gelenkkonturen. Akromion etwas höckriger als gewöhnlich, doch ïberall 
von deutlicher Corticalis begrenzt. Andeutung von Randwülsten. R echts (kranke Seite) Vergrößerung des Clavicularendes, Gelenkspalt ist gedeckt durch von beiden Seiten ausgehende unregelmäßige Prominenzen, vor allem spitzige Osteophyten am Akromion. Dieses ist an seiner oberen Kontur mit zahlreichen feinen Exkreszenzen besetzt und trägt vor allem eine sich gegen die übrige Kontur leicht abschnürende Randwucherung.

Diagnose: Arthritis chronica deformans articulationis acromio-clavicularis dextrae posttraumatica.

\section{Zusammenfassung:}

Im Laufe von 6 Jahren haben sich annähernd die gleichen durch Erkrankung des Akromialgelenks bedingten Beschwerden erhalten, die vor allem in Schmerzen und Steifigkeit bei der vertikalen Erhebung nach vorn, seitlich und vor allem rückwärts bestehen. Die Schmerzen werden im vorderen Deltoideusabschnitt lokalisiert. Der röntgenologische Befund läßt die Mög. lichkeit einer Fraktur, die klinisch wegen der Auftreibung des Clavicularendes angenommen wurde, offen, läßt aber deutlich eine Zerstörung des Gelenks durch Knochenappositionen an beiden Gelenkenden erkennen, mit den der Arthritis deformans eigenen Randwucherungen am Akromion. Das klinisch gesunde Gelenk zeigt röntgenologisch leichte Unregelmäßigkeiten.

Fal1 I2. Sp., E., 64jähriger Veteran (Diabetiker).

Im November I9I I stürzte Sp. über einen quer auf dem Trottoir liegenden Schlauch auf die rechte $\mathrm{Hand}$, während er in der linken zerbrechliche Gegenstände hielt. Erst etwa Anfang I913 bemerkte er Schmerzen in der rechten Schulter, die genau in der Gegend einer allmählich sich entwickelnden Geschwulst auf der Schulter zu lokalisieren waren.

Erste Untersuchung am 2I. IV. I9I3: Auf dem rechten Akromioclaviculargelenk eine halbkugelige, halb walnußgroße prall fluktuierende Geschwulst, die bei den Bewegungen des Gelenks knirscht und in der Gelenkgegend druckempfindlich ist. Patient kann den Hosenträger auf der Schulter nicht mehr tragen. Ausgiebige Schulterbewegungen sind schmerzhaft, besonders jedes Bewegen über die Horizontalc.

$R o ̈ n t g e n b i l d$ er ergeben unregelmäßige aufgefaserte Konturen der beiden Gelenkenden des Akromialgelenks und feine Schattierung der clarüber gelegenen Geschwulst. Am 24. IV. R e s ektion des Gelenks und des mit dem Gelenk kommunizierenden, eine geringe Menge Faden ziehender Flüssigkeit enthaltenden Schleimbeutels. Implantation eines gestielten Fettlappens in den Resektionsdefekt. 
Glatte Heilung unter sechstägiger Fixation. Dann Pendelübungen, später Massagen und Dampfduschen, die lange fortgesetzt werden, da Bewegungsstörungen und Schmerzen in mäßigem Grad länger anhalten. Wird Ende Oktober aus der Behandlung entlassen.

$\mathrm{N}$ a chuntersuchung am 27. I. I9I4: Hat hin und wieder noch Schmerzen bei stärkeren Bewegungen nach hinten und gibt an, daß beim vertikalen Erheben gelegentlich die Kraft plötzlich versage. Er meint abcr, ,er sei froh, daß es so gut geworden sei“. Die Be. hinderung sci viel geringer als vor der Operation. Die rückwärts konvexe, $8 \mathrm{~cm}$ lange Narbe umzielht das Gelenk an der hinteren Seite

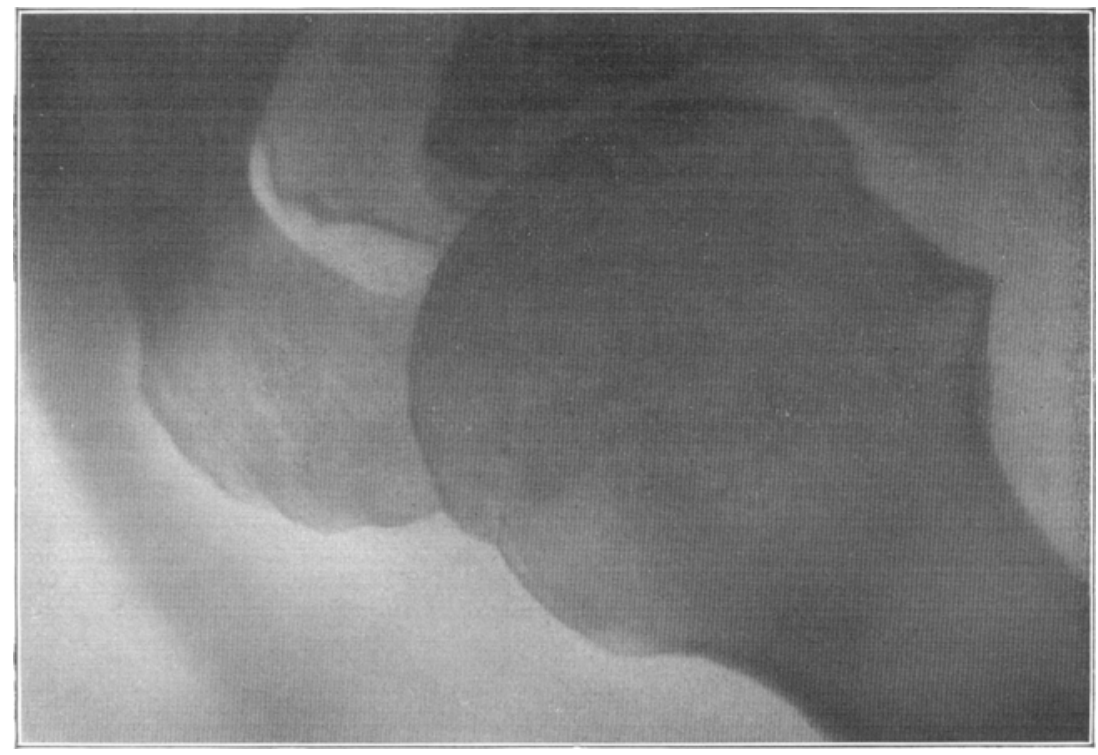

Fig. Io.

und endet etwas unterhalb des Akromions. Sic zeigt eine leichte Einziehung nach dem künstlichen Gelenkspalt hin. Das akromiale Ende des Schlüsselbeins springt nicht wesentlich vor, ist aber etwas scharfrandig und druckempfindlich. Unter dem Akromion kcin Druckschmerz, auch nicht in der Zirkumferenz des Oberarmkopfes. Achselheben geschieht beiderseits in gleichem Maße. Bei den vertikalen Erhebungen im neuen Gelenk leises Knirschen, kein Schmerz. Rönt . genuntersuchung ergibt besonders a f dem axillaren Bilde einengutklaffenden, scharfrandigen Gelenkspalt (vgl. Fig. Io). Auch auf dem vorderen Bild zeigt der Spalt absolut scharfe Ränder. Hier aber sind auf der oberen Kante der Clavicula kleine spitzige Prominenzen sichtbar. Links normale Verhältnisse. 


\section{Zusammenfassung:}

Bei einem Diabetiker entwickelt sich im Laufe von $5 / 4$ Jahren im AnschluB an ein indirektes Trauma (Fall auf die Hand) eine schmerzhafte deformierende Affektion des rechten Akromialgelenks mit chronischer Bursitis acromialis subcutanea. Wegen der Kommunikation der Gelenkhöhle mit der Bursitis und der sichtlich primären Erkrankung des Gelenks wird die Gelenkresektion mit der Exstirpation der vorderen Bursa verbunden. Es bleiben lange Zeit Beschwerden bei den Elevationsbewegungen zurück, die aber im Lauf eines Jahres im wesentlichen beseitigt sind, so daß der Arm schließlich vollkommen funktionstüchtig wird.

\section{b) ohne Trauma (primär).}

Fall I3. II. H., 68jähriger Kutscher.

Wollte am 18. XII. I9I2 auf einer Leiter, ca. $4 \mathrm{~cm}$ hoch stehend, Heu herunterholen, als die Leiter mit ihm zusammenbrach und er riicklings mit der rechten Schulter auf das Pflastcr fiel. Hinterher konnte er vor Schmerzen im Kreuz nur krumm gehen und hatte Schmerzen in der getroffenen Schulter, so daß er den Arm kaum bewegen konnte.

Erste Untersuchung am 25. I. 1913: Wird vom Arzt geschickt, da er noch immer ïber lebhafte Kreuz- und Schulterschmerzcn klagt. (Die Kreuzverletzung übergehen wir im folgenden, es lag keine Fraktur vor.) Der Patient, der für sein Alter sehr rüstig, nur sehr schwerhörig war, jammerte bei allen Bewegungsprüfungen über starke Schmerzen.

Röntgenuntersuchung: Die Konturen des rechten, kranken Akromialgelenkspaltes sind deutlich voneinander getrennt, dazwischen ein nach oben sich weitender, $2-4 \mathrm{~mm}$ breiter Spalt, in den sich kaudal ein schmaler, poröser, vom Clavicularende ausgehender Knochenschatten hineinlegt. Sehr auffallend sind die hochaufgeworfenen, ektropionierten, dorsalen Ränder der beiden Knochen, dic zackige, im Innern blasige, Auswüchse aufweisen. Verfolgt man die Schlüsselbeindiaphysen, so findet man bis an die mutmaßliche Ansatzstelle der coracoclavicularen Ligamente vielfältige spitzigere undi flachere Prominenzen mit aufgefaserten Rändern. In viel geringerem Maße ziehen sich diese Veränderungen am Akromion weiter (vgl. Fig. II). Links findet man nur geringfügigere Veränderungen an den oberen Kanten der Gelenkenden, noch kaum Auffaserungen der Ränder, vielleicht derselbe Proze $B$ in seinen Anfängen, jedenfalls 
verschwindend gegenüber den sehr auffallenden Störungen des rechten Gelenks.

$\mathrm{Nachuntersuchung} \mathrm{am} \mathrm{2I.} \mathrm{V.} \mathrm{19r3:} \mathrm{Schultergelenk} \mathrm{selbst}$ vollständig frei, Bew-egungsstörungen aber noch sehr erheblich. Übertreibung wahrscheinlich. Keine Atrophie, höchstens ganz geringe des Deltamuskels.

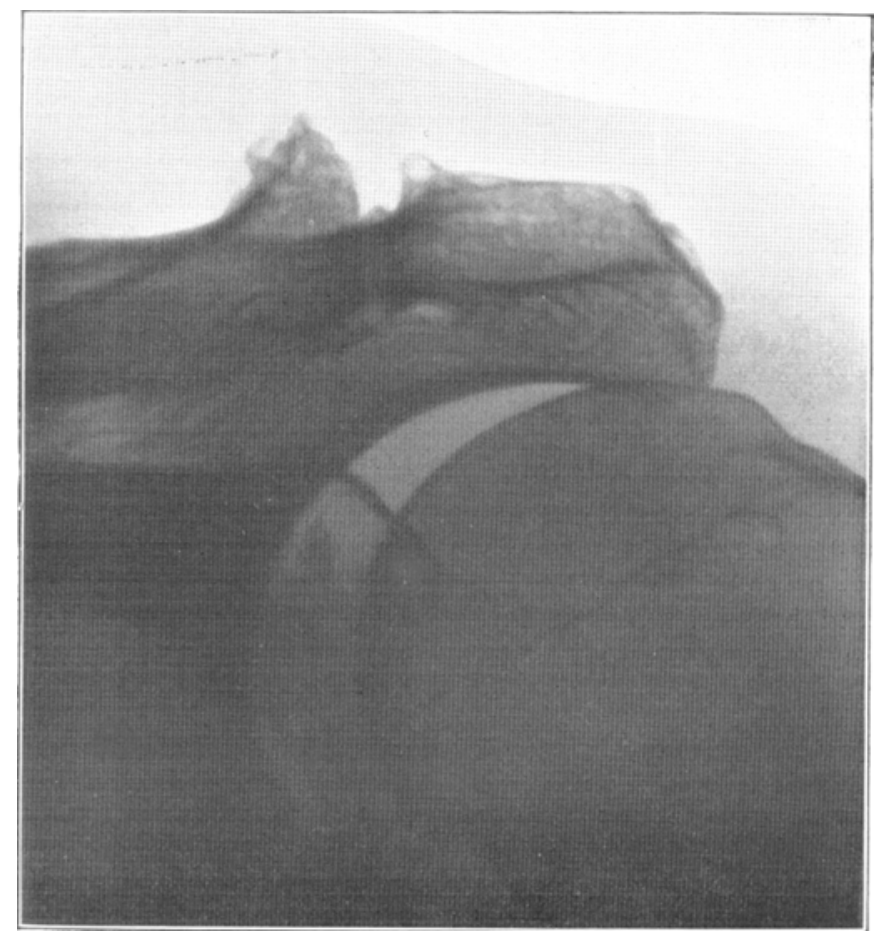

Fig. II.

Umfangsmaße:

Oberarme ro $\mathrm{cm}$ übcr dem Speichenköpfchen

Vorderarme $2,5 \mathrm{~cm}$ unter demselben

rechts: links:

$24,8 \quad 24,8$

$26,4 \quad 26,1$

Es wird Verschlimmerung cines vorhandenen Leidens des rechten Akromialgelenks als Unfallfolge angenommen und mit 35 Proz. entschädigt. Operativer Eingriff wurde abgclehnt.

Nachuntersuchung am 30. I. 1914: Äußeres Ende der Clavicula stark verdickt. Rand aufgeworfen. Lokaler Druckschmerz an diesem und um das Akromion herum, während Druck gegen das Gelenk selbst nicht besonders empfindlich ist. 
Die Arthritis acromio-clavicularis als wichtiges Glied in der Pathologie usw. 63 I

Rechter Arm wird nur bis 75 Grad seitlich erhoben, nach vorn bis zur Horizontalen. Bei diesen Bewegungen geh en Schulterblattund $\mathrm{Sch}$ lüsselbeinstärkermitalsauf derlinken Seite. Die Drehbewegung ist nur geringfügig eingeschränkt, dabei aber starkes Krachen, das sich am deutlichsten im Bereich des Akromialgelenks nachweisen läßt.

\section{Zusammenfassung:}

Bei H. hat sicher schon vor dem Unfall am I6. XII. I9I3 eine chronische deformierende Arthritis acromialis dextra bestanden, die vielleicht auch auf der anderen Seite in ihren Anfängen zu erkennen ist. Das offenbar sehr heftige direkte Trauma der rechten Schulter hat wohl irgendeine Verletzung des Gelenks herbeigeführt, die sich in den heftigen und schmerzhaften Bewegungsstörungen bemerkbar machte. Eine eingehende Bewegungsanalyse liegt in dem Falle nicht vor, war auch durch die Taubheit und Übertreibungssucht des Mannes erschwert, immerhin konnte auf Grund des klinischen Bildes mit Bestimmtheit die Ursache der Beschwerden im Akromialgelenk gesucht werden, das röntgenologisch die exzessiven deformierenden Veränderungen aufwies.

If all 14. G. N., 52jühriger Korkschneider.

Ist wegen Leistenbruchs nach $\mathrm{B}$ as s in i radikal operiert (17: bis 30. IV. stationär behandelt worden), klagt hinterher über $\mathrm{Sch} \mathrm{mer}$ zen in der rechten Schulter, die er aber schon seit 4 Jahren hat, die aber durch die vierwöchentliche Schonung verschlimmert seien.

Untersuchung am 30. V. 19I3: ̈̈ußeres Ende der Clavicula etwa auf die doppelte Größe verbreitert, stärkcres Prominieren als links. Sehr starkes Krachen im Gelenk bei den verschiedensten Bewegungen.

Köntgenbilder: Schwere Veränderungen der beiden Akromialgelenkenden: Auf Fig. I2 findet man den Gelenkspalt deutlich, die Corticalis beider Gelenkenden aber vielfach durch Arrosionen unterbrochen, die flache und rundliche Defekte besonders im Schatten der Clavicula bilden. Ein (auf dem Röntgenbild) spitziger Osteophyt lagert sich an die untere Kante an. Auf der oberen Kante findet sich ein ganzes Konvolut von blassen, kreisförmig angeordneten Schatten, die sich in einer subkutanen Bursa befinden könnten. Das Clavicularende ist vollkommen zackig geworden, anschlicßend aber ganz gesunde Diaphyse, die nicht atrophisch ist und keine periostalen Prozesse zeigt. Das Akromion ist nur am Gelenkende etwas porös und hat keinen ganz glatten Rand. 
Nachuntersuchung am 27. I. 19r4: Die Beschwerden sollen rechts ganz nachgelassen haben, es sollen dagegen im linken Oberarm gelegentlich Muskelschmerzen auftreten. Links weder damals noch jet\%t eine Erkrankung erkennbar.

B ef und: Akromialende der rechten Clavicula fast doppelt so groß wie das linke. Es läßt sich passivim Gelenk ka um be wegen, während das gesunde Gelenk die normale Federung von oben nach unten und Verschieblichkeit von hinten nach vorn aufweist. Es fehlt jede Muskelatrophic. Rechts stcht die Scapulabei Hängelagedes Oberarms weiterab vom

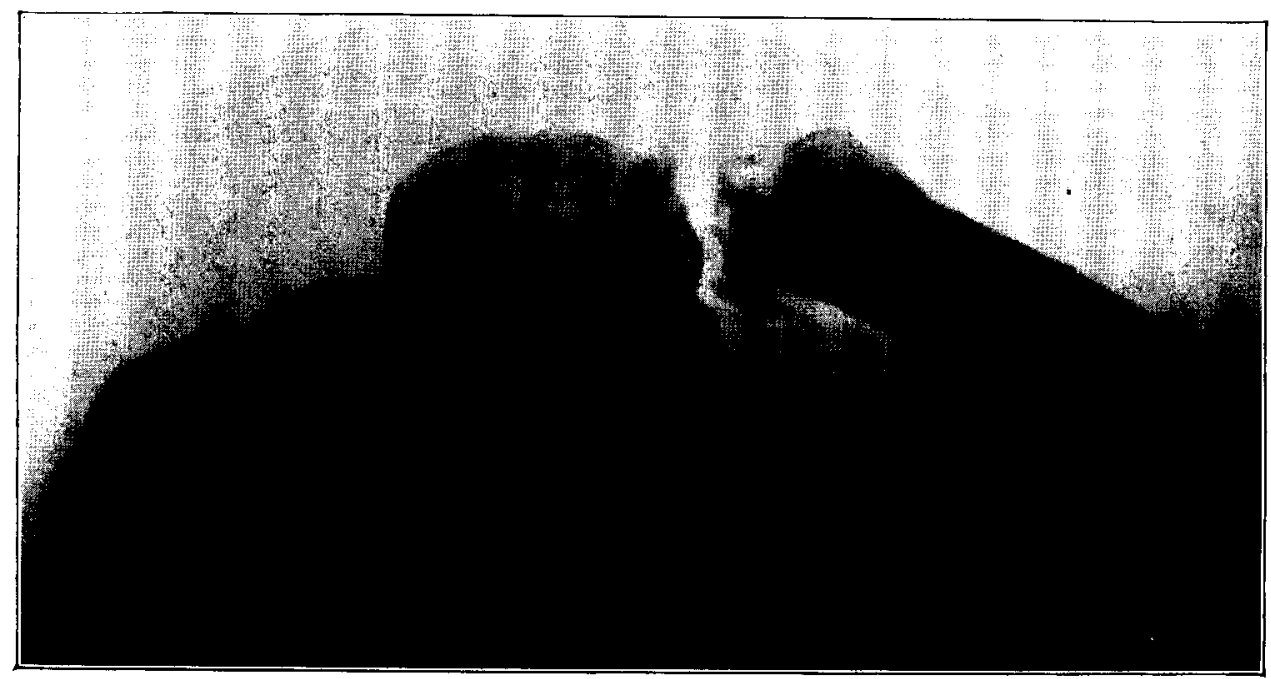

Fig. I 2.

B rustkorb und nähert sich mit ihrem unteren Winkel der Dornenreihe, so daß der mediale Rand etwas von oben außen nach unten medial geneigt ist. Der linkseitige steht eher in umgekehrter Richtung. Beim Achselhebcn dreht sich rechts die Skapulaspitze etwa so weit, daß der innere Rand vertikal steht, während sich links der untere Winkel etwas auswärts dreht. Dic Bewegungen der Arme werden fast gleich ausgefüht und ohne nennenswerte Beschwerden. Beim Elevieren über dic Horizontale findet man in beiden Akromialgelenken feines Knirschen, rechts ganz leisen Schmerz. Bei den Rückwärtsbewegungen, die in glcichem Ausmaße möglich sind, drückt sich bei der Rotation der Clavicula um die Längsachse über vorn nach unten, wie bei dicsen Bewegungen die Regcl ist, das rechte Sternalende stärker aus seinem Gelenk heraus als das linke. 
Zusammenfassung:

Gelegentlich einer Bassinioperation findet man bei einem 52 jähr. Manne ein schwer verändertes Akromialgelenk, ausgesprochen Arthritis deformans (jede andere Arthritis ist unwahrscheinlich), die seit 4 Jahren mäßige Schmerzen verursacht, ohne die Arbeitsfähigkeit zu beeinträchtigen. Beschwerden haben sich offenbar durch die Ruhe nach der Operation verschlimmert und verschwinden dann wieder fast ganz im folgenden Jahre. Klinisch macht sich die Affektion dann nur durch leichte Behinderung der vertikalen Elevation und geringfügige Störungen der Achselhebung bemerkbar. Abnorme Einstellung der Scapula in der Ruhelage, sowie veränderte Funktion des Sternalgelenks bei der Rotation der Clavicula um ihre Längsachse, machen eine teilweise Ankylose des Akromialgelenks wahrscheinlich.

In den sämtlichen Fällen (2--I4) liegen entzündliche Erkrankungen des Akromialgelenks vor. Bis auf einen (Nr. I4) werden Verletzungen als vermutliche Ursache vom Kranken angegeben, die in 6 Fällen direkt, und zwar meist von hinten die Schulter trafen, 7 mal indirekt auf sie einwirkten. Unter der zweiten Gruppe handelte es sich 4 mal um Fall auf dic Hand, I mal auf den Ellenbogen und im Fall i I um eine Zug- und Reißwirkung am Arm kranialwärts. Das Trauma mußte in der Mehrzahl auch vom ärztlichen Standpunkt als die Ursache des Leidens anerkannt werden, nur in Fall 13 waren die Veränderungen des Gelenks so fortgeschritten, daß man sie unbedingt als älteren Datums ansprechen mußte, das Trauma nur als Verschlimmerungsmoment gelten lassen konnte. 8 mal schlossen sich die subjektiven Störungen sofort an die Verletzung an und machten die Leute mit einer Ausnahme arbeitsunfähig. In den drei restierenden Fällen handelte es sich einmal um ein Rezidiv durch größere Anstrengung der ein Jahr zuvor verletzten Schulter (Fall 4), einmal traten erst $1 \frac{1}{2}$ Monat danach nennenswerte Beschwerden ein, und im Fall I2 erst nach $5 / 4$ Jahren. Die Erkrankung trat in 9 Fällen bei Männern der arbeitenden Bevölkerung zwischen 50 und 70 Jahren auf, je einmal bei jüngeren von 27 , 36,38 und 40 Jahren. Einmal traf sie eine 67 jähr. Frau. 
Die jugendlichen Fälle verteilen sich sämtlich auf die ersten Gruppen, fallen entweder unter die akute Arthritis (Fall 4), oder die an Frakturen, oder doch sicher nachgewiesene Traumen des Clavicularendes sich anschließende chronische Form (Fall 6 und 7), während die mit schweren deformierenden Veränderungen emhergehenden chronischen Erkrankungen dem höheren Alter angehören.

Trotz der Mannigfaltigkeit der pathologisch-anatomischen Krankheitsbilder sind bestimmte Symptome allen Fällen eigen und müssen als differentialdiagnostische Erkennungsmerkmale angesehen werden. Von der Arthritis humeroscapularis sowie den Affektionen des subdeltoiden Raums unterscheidet sich die Arthritis acromialis zunächst durch die a uf der Schulterhöhe mittels der flachen Hand erkennbare Krepitation, die meist auch dem Ohre vernehmbar, gewöhnlich etwas gröberen, knackenden, krachenden, nicht knirschenden Charakter hat. Nicht ihr Vorhandensein, sondern ihre Lokalisation ist das Merkmal, denn im allgemeinen darf auf Krepitation überhaupt nicht zu viel Gewicht gelegt werden, es geschieht das in viel zu hohem Grade. Besonders vom Kniegelenk wissen wir, daß reichliches Knirschen vorhanden sein kann, ohne eine Spur von Beschwerden. Auch am Schultergelenk findet man, zumal im höheren Alter, viel häufiger mit Geräuschen verbundene Bewegungen als völlig geräuschlose. Mit dem Akromialgelenk ist es nicht anders: Ganz beschwerdefreie Gelenke können krepitieren, wie es bei mehreren unserer Fälle auf der gesunden Seite angegeben ist. Sehr lehrreich ist in der Beziehung Fall 4, wo die gesunde Seite Krepitation verursacht, auf der kranken Seite aber der Erguß die Geräusche aufhebt.

Indes gibt eine auf die Akromialgegend beschränkte Krepitation doch den bestimmten Hinweis auf das Akromialgelenk und unterscheidet sich ganz wesentlich von den bei Schultergelenkerkrankungen in der Umgebung des Humeruskopfes vor allem bei Rotationsbeginn auftretenden, meist auch feineren knirschenden Geräuschen. Diese Qualität spricht man auch den Geräuschen bei der Bursitis subacromialis zu, die durch ihre Entstehung dicht unter dem Akromion wohl zu Verwechslungen mit denen 
Die Arthritis acromio-clavicularis als wichtiges Glied in der Pathologie usw. 635

des Akromialgelenks Anlaß geben können. Immerhin ist auf die Lokalisation der Geräusche in erster Linie zu achten, die man am besten mit der flachen Hand unter Vornahme bestimmter passiver und aktiver Bewegungen sehr eingehend prüft. Nicht selten allerdings muß man lange forschen, bis man ihren Ausgangspunkt einigermaßen klargestellt hat. Je nach dem Entstehungsort im oder unter dem Gelenk, der Fortleitung durch die Knochen kann die Feststellung erschwert werden. Diagnostischen Wert möchten wir nur dann auf sie legen, wenn sie mit einiger Deutlichkeit auf das Gelenk zu begrenzen sind und gleichzeitig mit schmerzhafter Hemmung derjenigen Bewegung auftreten, die sie herbeiführt.

Wir kommen damit auf die gewichtigste Untersuchungsmethode der akromialen Gelenkerkrankungen, die Funktionsprüfung. Die Eigenart des Gelenks mit seiner Lockerkeit, seinen kleinen Gelenkflächen und langen Hebelarmen läßt wohl nur in den seltensten Fällen eine Kontrakturstellung zustande kommen. In Fall 6 und 14 bedingten allerdings die beträchtlichen Auftreibungen des Clavicularendes, einmal durch Callus, das andere Mal durch Randwucherungen bei Arthritis deformans eine teilweise Ankylose des Gelenks, die zu einer merklichen Abweichung im Verhalten der Scapula führten. In Fall 6 stieg die Scapula bei der Achselerhebung nicht senkrecht an wie auf der gesunden Seite, sondern drehte sich mit ihrem unteren Winkel frühzeitiger auswärts. Verhinderte man diese Drehung, so konnte die Schulter vom Kranken weniger weit erhoben werden. In Fall I 4 befand sich der Angulus infer. scapul. in der Ausgangsstellung der Wirbelsäule abnorm nahe und führte infolgedessen bei der Achselerhebung eine von der gesunden Seite abweichende Bewegung aus.

Die geschilderten Differenzen weisen mit Bestimmtheit auf eine Beschränkung der normalerweise besonders großen Mobilität im Akromialgelenk, nicht etwa auf eine vollständige Ankylose, bei der sehr viel bedeutendere Unterschiede erkennbar sein müßten, dic man sich leicht theoretisch ableiten kann.

Bei der Analyse der Bewegungsstörungen war das Hauptgewicht auf ihre Abgrenzung von denen bei anderen Schulterversteifungen zu legen. Wie zu Eingang besprochen, 
kommt es bei der Bursitis subacromialis und den Erkrankungen des subdeltoiden Raums fast ausschließlich zur Abduktionshemmung. Alle Autoren legen den größten Wert auf dies differentialdiagnostische Zeichen, dagegen kennzeichnet sich die Erkrankung des Schultergelenks sehr bald in schnell zunehmender Rotationshemmung - neben Versteifung in den anderen Richtungen; am klarsten sind diese Verhältnisse von Payr und Lange dargestellt, worauf wir verweisen möchten.

Nachdem wir die intimen Beziehungen des Akromialgelenks zu allen Funktionen der Schulter eingehend erörtert haben, ist es von vornherein plausibel, daß für das Akromialgelenk auch die Vielseitigkeit der Bewegungshemmungen charakteristisch sein muß. Der Grad der Funktionsstörungen hängt sicher in jedem einzelnen Fall von der Beschaffenheit des Gelenks ab, und vor allem von der pathologischen Abänderung des ja schon normalerweise sehr wechselvollen Mechanismus. Es lassen sich aber doch auf Grund unserer Beobachtungen allgemeingültige Regeln aufstellen, die vielleicht in mancher Richtung noch der Ergänzung und Verfeinerung bedürfen, die aber für die Diagnostik und das Verständnis der Akromialgelenkerkrankungen einen brauchbaren Wegweiser liefern.

Wir verweisen wieder auf den lockeren Bau des Gelenks, der es verständlich macht, daß diejenigen Armbewegungen, die mit den ausgiebigsten Skapularbewegungen einhergehen, durch die lokalen Gelenkveränderungen wohl relativ spät gehemmt werden. Es sind das die Vorwärtsbewegungen, die durch das Akromialgelenk den größten Zuwachs erfahren (vgl. S. 600, Mollier, Fick) und bei denen die Bewegung im Akromialgelenk um die vertikale Achse in ihrer freisten Richtung stattfindet. Es war daher die Elevation nach vorn in unseren Fällen meist über die Horizontale ausführbar. Bei der Ähnlichkeit der Funktionen des Akromialgelenks bei allen Elevationsbewegungen des Arms ist es verständlich, daß auch die Abduktion in relativ geringem Grade beeinträchtigt ist, immerhin pflegt sie etwas stärker gehemmt, als jene, und bald über der Horizontalen Schwierigkeiten zu bereiten.

Für die Rückwärtsbewegung steht nur ein geringer Bewegungsgrad im Akromialgelenk zur Verfügung, daher ist hier 
auch der Ausfall meist ein sehr merkbarer, doch unterliegt gerade die Störung dieser Bewegung einer wohl durch die wechselnden anatomischen Verhältnisse des Gelenks verursachten Variation. Häufig finden wir die Bewegung gegen Ende sehr schmerzhaft und mit harter Krepitation im Gelenk verbunden. Diese Beobachtung ist durchaus verständlich, da das Akromialgelenk erst in der Endphase der Rückwärtsführung des Arms in Funktion tritt.

Als wichtigstes Charakteristikum der Akromialgelenkerkrankungen müssen wir die in mehreren Fällen verschiedener Gruppen eingehend mitgeteilten Störungen der drei Achselbewegungen betrachten. Bewegungen, die unabhängig vom Schultergelenk vor sich gehen und daher auch bei dessen Erkrankungen nicht in nennenswertem Maße primär gehemmt sein können.

Die Achselverschiebungen werden vor allem durch Sternalgelenkbewegungen vermittelt, und so muß es zunächst überraschen, wenn wir gerade hier nach charakteristischen Störungen fahnden.

Wir haben aber eingangs ausgeführt, daß das Akromialgelenk auch bei diesen Funktionen in typischer Weise beteiligt ist. Da diese Bewegungen dem Gelenk weniger bequem sind, und damit weniger ausgiebig und frei, müssen gerade sie bei Gelenkerkrankungen besonders gehemmt und schmerzhaft werden. Da der Kranke selbständige Bewegungen der Schulter nicht kennt und über ihren Ausfall nicht klagen kann, muß man eigens auf sic achten. Man findet dann z. B. beim vertikalen Erheben ein Zurückbleiben der kranken Seite von einigen Zentimetern (Maximum der Erhebung ist nach meinen Erfahrungen $10-12 \mathrm{~cm}$ ) oder Krepitation und Schmerz an Ort und Stelle bei einer bestimmten Phase der Bewegung. Auch ist auf das Verhalten der Scapula zu achten, die bei Versteifungen des Gelenks nicht parallel aufwärts steigt, sondern mit einer Außendrehung des unteren Winkels, die auf der gesunden Seite fehlt. Dieselben Störungen sind bei den Vor- und Rückwärtsbewegungen manchmal in noch höherem Maße ausgeprägt, besonders bei Erguß ins Gelenk empfindet der Kranke das Gefühl der Spannung: wie einer sich ausdrückte (Fall 4), wie wenn ihn jemand halten wollte“.

Wo diese bezeichnenden Störungen der Achselbewegungen 
vorliegen, kann man mit annähernder Sicherheit eine Erkrankung des Akromialgelenks diagnostizieren.

Die Rotationsbewegungen des Arms um seine Längsachse pflegen nur wenig in ihrer Ausgiebigkeit beeinträchtigt zu sein, doch hört man gerade über sie klagen; bald können die Kranken nicht ohne Schmerzen auf ihren Rücken fassen, bald nicht genügend von hinten ausholen (beim Mörtelbewurf z. B. oder Asphaltstampfen). Diese Tatsache stimmt mit der Beobachtung überein, daß die Funktionsstörungen um so stärker sind, je mehr die Beanspruchung des Gelenks im Mißverhältnis steht zu den Bewegungen um die typischen Achsen, je mehr es sich um Hebelbewegungen handelt und das Gelenk zum Hypomochlion wird. Das ist bis zu einem gewissen Grade bei den Rotationsbewegungen der Fall. Man kann bei mageren Menschen diese Wirkung sehr gut fühlen.

Recht verschiedenartig sind die von den Verletzten geäußerten subjektiven Beschwerden. Der Schmerz wird meist a uf der Höhe der Schulter oder etwas hinter derselben emp. funden, fast nie genau im Gelenk. In der überwiegenden Mehrzahl der Fälle zieht er sich von da über die $A$ uBenseite des Deltoideus nach dessen Ansatz oder weiter nach dem Ellenbogen, so daß man versucht ist anzunehmen, da $\beta$ es sich um eine Ausstrahlung im Axillarisgebiet handelt. Der Axillaris ist nach Fick an der Versorgung des Akromialgelenks beteiligt und sendet anderseits sensible Zweige zur Außenseite des Oberarms (Cutan. brach. lateral., Anastomose mit dem Cutan. brach. poster., sowie Äste durch den Deltoideus). Doch konnten wir uns vielfach des Eindrucks nicht erwehren, daß der Deltoideus selbst vielleicht infolge seines Ansatzes am Akromialgelenk - diese Schmerzen hervorruft. Darauf wurden wir in erster Linie geführt durch den vereinzelt in seinem vorderen Bereich vorhandenen Druckschmerz, den wir deswegen auf den Muskel beziehen inußten, weil der Schmerz bei Vorwärtselevation des Armes und brettharter Kontraktion des Muskels nicht nachließ. Nicht einmal erinnern wir uns indes von einem Kranken die Angabe erhalten zu haben, daß an der Innenseite des Arms Schmerzen bestiunden, wie sie als charakteristisch für die Bursitis subacromialis bezeichnet werden. 
Die Arthritis acromio-clavicularis als wichtiges Glied in der Pathologie usw. 639

Einige Kranke klagten über plötzliches Versagen der Kräfte bei gewissen Bewegungen, besonders bei der Abduktion des Arms, wobei sie ein „knupsendes“ Geräusch hörten und fühlten. Man findet in solchien Fällen, ganz ähnlich wie es Bähr (vgl.S.605) beschreibt, beim Herunterlassen des seitlich erhobenen Armes, etwa beim Überschreiten der Horizontalen, ein dem Repositionsschnappen bei der Luxation ähnliches Geräusch, das eben klangmalerisch sehr treffend als „Knupsen“ bezeichnet wird. In demselben Moment lassen die Kranken den Arm schlaff herunterfallen und empfinden einen lästigen, manchmal heftigen Schmerz.

Die Ähnlichkeit mit der Bährschen Beschreibung ist sinnfällig; indes konnten wir uns dabei nicht von einer nennenswerten Dislokation im Akromialgelenk überzeugen, die von Bähr als Ursache angenommen wird. Wir glauben vielmehr, daß das Symptom mit einer Unebenheit im Gelenk durch Verletzung der Gelenkenden oder des Zwischenknorpels nach Analogie der Meniscusverletzungen am Knie oder Kiefergelenk in unseren Fällen hinreichend erklärt ist.

Sehr interessant ist uns die Mitteilung Bährs, daß in seinem Falle, indem es sich übrigens auch um Folgen einer ,Schulterkontusion" handelte, besonders Schmerz beim Einstecken der Hand in die Tasche und Einstemmen in die Seite auftrat. Bei diesen Bewegungen wird die Achsel gehoben, also gerade diejenige Bewegung ausgeführt, deren Schmerzhaftigkeit und Behinderung wir als wichtigsten Hinweis für die Erkrankung des Akromialgelenks ansehen.

Eine fernere Klage unserer Kranken, $d a B$ sie nicht auf der verletzten Schulter liegen können, daß sie infolgedessen nachts gestört werden, ist fast selbstverständlich. Beim Liegen auf der Seite liegt entweder die Körperlast auf dem Außenrande des Akromions und dem Deltamuskel, wobei das kranke Akromialgelenk also direkt belastet wird, oder die Schulter wird vor- und einwärts verschoben - der Körper ruht auf dem Blatte der Scapula -, dabei dreht sich das Schulterblatt im Akromialgelenk und wird wahrscheinlich durch die Körperlast außerdem in gewissem Grade gehebelt, so daß der Schmerz erklärt ist.

Die Diagnose der Arthritis acromialis wird natürlich wesentlich erleichtert bei äußerlich wahrnehmbaren Verände- 
rungen am und um das Gelenk, wie sie bei der frischen Entzündung durch den Gelenkerguß oder die Schwellung der Weich. teile der Nachbarschaft, besonders auch des subkutanen Schleim. beutels gegeben sein können oder nach Frakturen am akromialen Ende der Clavicula, wie bei der Arthritis deformans durch die Auftreibung der Gelenkenden zustande kommen. Auch eine abnorme Lockerung oder Fixierung des Schlüsselbeinendes im Gelenk kann diagnostischen Wert haben, immer vorausgesetzt, daß eine merkliche Differenz gegenüber der gesunden Seite nachweisbar ist.

In unseren Krankengeschichten ist verschiedentlich darauf hingewiesen, daß eine meßbare Atrophie der Muskulatur nicht nur des Armes, sondern auch der Schulter bei den reinen Fällen von Akromialgelenkentzündung nicht eintritt. Ich möchte das als charakteristisch und besonders wichtig für die Abgrenzung der Affektion von Schultergelenkerkrankungen ansehen. Auch in dem Bährschen Falle fehlte sie.

Ein ausschlaggebendes, aber in den Frühfällen natürlich manchmal versagendes Hilfsmittel für die Diagnostik der Arthritis acromialis sind die Röntgenstrahlen. Allerdings ist ihre Technik für unser Gelenk nicht ganz einfach, und man kan’x ruhig zugeben, daß es selbst bei genauer Beherrschung derselben stets etwas Glücksache ist, ob man wirklich einwandfreie befrie digende Bilder erhält.

Hinsichtlich der Sagittalaufnahme ist es irrelevant, of man von vorn oder vom Rücken exponiert. Da der Abstand des Akromialgelenks von der mittleren Frontalebene der Schulter nach vorn nur unerheblich ist, die Entfernung des Gelenks von der Platte also bei beiden Einstellungen ziemlich die gleiche ist, werden auch Vergrößerung und Zerstreuung identisch sein. Wir haben mit der ventrodorsalen Richtung die besten Erfahrungen gemacht. Man hat bei diesen Aufnahmen auf zweierlei zu achten:

I. der Gelenkspalt soll nach Möglichkeit in seiner richtigen (frontalen) Breite zur Abbildung kommen,

2. seine Projektion darf sich nicht mit der des Akromions decken.

Zur Erfüllung der ersten Bedingung muß der Normalstrahl 
genau auf den Gelenkspalt eingestellt werden und diesen in seiner Längsrichtung durchsetzen. Die Deckung zwischen Gelenk und Akromion meidet man, wenn man den Normalstrahl etwas kaudalkranial geneigt gegen die horizontale Sagittallinie einfallen läßt.

Danach gestaltet sich diese Aufnahme folgendermaßen: Man lagert den Kranken wie zu einer Schulteraufnahme, indem man die gesunde Seite so hebt und durch Kissen feststützt, daß die Scapula der kranken Seite möglichst flach aufliegt, unter ihr die Platte. Eine Aufrichtung des Oberkörpers ist aber für die Akromialgelenkaufnahme nicht erforderlich, da der Strahlengang nicht wie bei der Schulteraufnahme kranio-kaudal, sondern eher in der umgekehrten Richtung geneigt werden muß. Der Tubus der Kompressionsbiende wird nun mit leicht lateraier und kaudaler Neigung seines oberen Endes auf das gut fühlbare Gelenk zentriert. Die Expositionszeit ist der geringen Dicke und Dichte des Akromions und der Clavicula anzupassen, nicht der des Humerus.

Bei einer solchen normalen Sagittalaufnahme des Akromialgelenks wird der Gelenkspalt in seiner Längsrichtung getroffen und in ganzer Breite richtig abgebildet, ferner dadurch vom Akromionschatten isoliert, daß dieses leicht von unten getroffen wird, so daß sich sein Schatten gewissermaßen entfalt et. Während bei Schultergelenkaufnahmen der sagittale Verlauf des Akromions in Form eines schmalen Rechtecks sich im Schatten der frontalen Schultergräte abbildet, löst sich diese Deckung bei unserer Aufnahme so auf, daß der Akromialschatten die Fortsetzung der Spina bildet und an seiner Innenseite der Gelenkspalt sichtbar wird.

Man hat natürlich zu vermeiden, daß der Strahlengang nicht zu sehr axial wird und erkennt die richtige Einstellung in dieser Hinsicht daran, ob der Spalt zwischen dem Schlüsselbein und der Schultergräte nicht $\mathrm{zu}$ breit ausfällt, ferner das am akromialen Ende abgeflachte Schlüsselbein sich schmal darstellt.

Es ergibt sich von selbst, daß mit dieser Aufnahmetechnik auf eine tadellose Darstellung des Schultergelenks verzichtet werden muß. Der Humeruskopf deckt sich wegen der kranialen Richtung mit dem hinteren Akromialrand und wegen der lateralen Einstellung mit der Cavitas glenoidalis scapulae. 
Da nun in vielen Fällen eine Kontrolle des Schultergelenks unentbehrlich ist, um arthritische Veränderungen hier auszuschließen, wird eine zweite Sagittalaufnahme notwendig sein mit leicht medialer und kranialer Neigung des Tubus zur Abbildung des Humeroskapulargelenkspalts.

Sehr häufig wird man aber auch mit diesen beiden Aufnahmen nicht auskommen, sondern Kontrollbilder sowohl derselben Seite als a uch der gesunden anfertigen müssen, zumal wenn es sich um die Frage der Obliteration des Gelenkspalts handelt. Man hat stets daran zu denken, daß die anatomischen Verhältnisse des Akromialgelenks wechselnde sind, der Spalt nicht immer in demselben Maße lateral schräg verläuft, auch das Verhalten des Akromions zur Spina wohl nicht immer das gleiche ist. Andererseits hat man an dem Gelenk der anderen Seite einen guten Anhalt, denn bei demselben Individuum scheinen unter gesunden Verhältnissen die Gelenke identisch gebaut zu sein.

Ist die besprochene Sagittalaufnahme gelungen, bleiben aber dennoch Fragen offen, so ist entschieden eine axiale Aufnahme, die also zu der ersten annähernd senkrecht steht, zu empfehlen. In vielen Fällen wird man dadurch den gewünschten Aufschluß erhalten. Sie scheinen sich bisher keiner Beliebtheit zu erfreuen, da ich sie in allen einschlägigen Arbeiten vermißt habe. Ich wies schon oben gelegentlich der Besprechung des Stiedaschen Krankheitsbildes auf sie hin. Nur Grashey bildet in seinem Atlas typischer Röntgenbilder vom normalen Menschen eine solche Aufnahme ab, die er als „,kaudo-ventrodorsal“ bezeichnet. Sie soll bei außenrotiertem und eleviertem Arm bei Rückenlage, Anlegung der Scapula an die Platte und Einstellung auf die Axilla nahe dem Gelenk angefertigt werden. Wie die Aufnahme zeigt, bildet sich das Gelenk zwischen Akromion und Clavicula vor dem Humerusschatten dabei ab, indes beweist der schmale Schatten der Clavicula, daß sie nicht eigentlich von der Unterfläche her getroffen ist, sondern mehr von vorn.

Ich habe diese Aufnahmen schon seit langem angewandt, mich aber dabei überzeugt, daß sie für das Akromioclaviculargelenk nicht so brauchbar sind, wie eine andere, jetzt zu beschreibende Technik: 
Der Kranke wird mit der Brust auf ein auf dem Untersuchungstisch liegendes etwa Io $\mathrm{cm}$ hohes Kissen gelegt, dic Schulter vorm Vornüberfallen durch eine besondere Unterlage geschützt, der Oberarm maximal einwärts rotiert neben den Oberkörper gelegt, wozu der Ellenbogen leicht gebeugt und die Hand mit dem Handrücken in die Lendengegend gelegt werden muß. Das Olecranon sieht dabei lateral, der Epicondylus externus humeri liegt auf. An die Schulterhöhe wird vertikal eine Platte 13: I 8 gelehnt und mit Sandsäcken fest gestützt. Die obere Schulterkontur soll etwa rechtwinklig zur Körperlängsachse laufen. Nun kommt man mit dem, mit der Öffnung um wenige Grade abwärts gegen die Horizontale geneigten Blendenzylinder von hinten möglichst dicht an die Achsel heran, die man etwa in der Richtung von der hinteren Achselfalte nach dem Akromialgelenk hin durchleuchtet. Durch Einstellung des Normalstrahls über dem Schulterblatthals vermeidet man dessen Deckung mit dem Gelenk. Eine gute Zentrierung ist unerläßlich.

Bedienen wir uns der Grasheyschen Nomenklatur, so müssen wir von einer $\mathrm{kaudo-dorsoventralen} \mathrm{Aufnahme}$ sprechen. Es scheint uns nur mit dieser Technik möglich, den Akromialgelenkspalt wirklich in axialer Richtung von seinen knöchernen Nachbarteilen zu isolieren, insbesondere vom Humeruskopf, der hierbei vor das Gelenk projiziert wird. Indes sind die Aufnahmen recht mühsam, zeitraubend und glücken nicht in allen Fällen gleich befriedigend.

Sind sie gut gelungen, so entsteht ein Bild, wie es Fig. Io bringt, auf dem man den Akromialgelenkspalt hinter dem Humerusschatten isoliert erkennt. Das akromiale Schlüsselbeinende liegt dabei in einer Ecke zwischen dem Akromion hinten, dem Humeruskopf vorn und der Schulterpfanne medialwärts. Das Collum scapulae erscheint schlank, entsprechend seiner axialen Durchleuchtung, das Akromion von der Fläche dargestellt. Das Akromialgelenk wird ebenfalls fast genau axial projiziert, so daß man es insagittaler und frontaler Richtung ganz übersieht.

Die Ergebnisse der Röntgenuntersuchung sind in den einzelnen Fällen mitgeteilt. Gerade auf ihnen beruht im wesentlichen die Gruppeneinteilung der Fälle: die frischen oder 
subakuten Entzündungen, die auf dem Radiogramm keine Veränderungen sehen lassen, die durch Fraktur am akromialen Schlüsselbeinende verursachten Gelenkschädigungen, bei denen man die Fragmente oder Callusappositionen deutlich erkennt, ferner die ohne nachweisbare Fraktur einhergehenden chronischen Arthritiden, die am Clavicularende deformierende Veränderungen erkennen lassen, und endlich die äußerst charakteristischen Fälle von Arthritis deformans. Ihre Äußerungen unterscheiden sich offenbar nicht von denen an anderen Gelenken. Wir finden vor allem in den vorgeschrittenen Fällen (I I-I4) stark aufgeworfene Randwucherungen am Clavicular- und am Akromialende, während wir bei den an Kontusion und Fraktur des Clavicularendes sich anschließenden Arthritiden ganz vorwiegend Apposition am Schlüsselbein beobachten. Auch dadurch charakterisieren sich die Fälle von Arthritis deformans, daß die Appositionsvorgänge noch weit vom Gelenk ab die Knochenenden deformieren. Diese pathologischen Unregelmäßigkeiten der Arthritis deformans lassen sich wohl von den, am Gesunden selbstverständlich durch die Tuberositäten bedingten Unebenheiten unterscheiden, da diese von Corticalis scharfrandig bedeckt sind, jene nicht. Haenisch hat bei alten Fällen von Arthritis deformans des Schultergelenks auch am Akromion osteophytische Spitzenbildungen gesehen.

Ich bemerke nochmal ausdrücklich, daß unsere Fälle niemals Arthritis deformans der Schulter oder andere entzündliche Veränderungen dieses Gelenks klinisch oder röntgenologisch erkennen ließen ${ }^{1}$ ). Danach scheinen sich die beiden Erkrankungen auszuschließen. Es dürfte das auch ganz erklärlich sein. Führt ein Trauma zur Schädigung des Akromialgelenks, so hat es sich hierbei erschöpft oder hat eine Richtung gehabt, die eben gerade das Schultereckgelenk treffen mußte, eine Hebelwirkung ausgeübt, die hier ihr Ende fand. Auch dürfte ein erkranktes Akromialgelenk unwillkürlich eine gewisse Schonung der Schulter zur Folge haben. Indes wollen wir darum nicht sagen, daß die traumatische Akromialgelenkentzündung

I) In meinen sämtlichen Fällen ist eine genaue Untersuchung des Schultergelenks erfolgt, auch wo der Kürze halber nicnt ausdrücklich in der Krankengeschichte darauf hingewiesen ist. 
nur allein vorkommen kann. Wie wir über einen Fall (Io) berichteten, der außerdem auf derselben Körperhälfte einen typischen Radiusbruch aufwies, so haben wir auch Kombinationen mit Luxatio humeri, Fractura tuberculi majoris usw. gesehen; Fälle, bei denen ev. als störende Folge nur die Akromialgelenkaffektion zurückbleiben kann. Wir wollen hierauf an dieser Stelle nicht näher eingehen, ebensowenig wie auf die sicher nicht ganz selten eintretende Schädigung beider Claviculargelenke, wie sie z. B. im Fall 8 zur Beobachtung kamen.

Die Abgrenzung der Akromialgelenkerkrankung von den genannten Komplikationen wird, wenn sie im Vordergrund der Beschwerden steht, auf Grund der angegebenen diagnostischen Merkmale meist möglich sein, schwieriger wird wohl manchmal die Erkennung einer begleitenden Bursitis subacromialis sein wegen ihrer direkten Benachbarung. Vielleicht wird man finden, daß sie nicht ganz selten neben der Arthritis acromialis auftritt. In Fall 8 u. ro mußte aus den diffusen knirschenden Geräuschen bei der Rotation an eine Mitbeteiligung des Schleimbeutels bzw. des subakromialen Raums gedacht werden.

Wir verwandten bei dieser Gelegenheit wie auch bei mehreren anderen Fällen die schon auf Seite 589 angeführte Injektıon eines Anästhetikums ins Gelenk bzw. in den subdeltoiden Raum, und erhielten so eine Bestätigung unserer Annahme, daß das Gelenk und der Schleimbeutel beide erkrankt seien, dadurch, daß sukzessive die Beschwerden beseitigt wurden. Das Verfahren ist ein recht bequemes unschädliches diagnostisches Hilfsmittel, das gerade bei der Unterscheidung zwischen Akromialgelenkaffektion und einer solchen des darunter gelegenen Raumes sehr empfehlenswert erscheint, wenn man auch stets zuerst versuchen wird, ohne eine solche „Eselsbrücke“ zum Ziele zu kommen.

Es liegt in unserer Absicht, in einem geeigneten Falle auch einmal durch Injektion einer für Röntgenstrahlen schlecht durchlässigen Flüssigkeit (besonders Collargol) die Darstellung der Bursa subacromialis zu versuchen, um ihre Beziehungen zum subdeltoiden Raum einerseits, zum Akromialgelenk andererseits röntgenologisch zu untersuchen. Payr hat bekanntlich diese Injek- 
tionen zur Darstellung der Überreste des Gelenkkapselschlauches vor der operativen Mobilisierung der Ankylose verwandt und empfohlen.

Die Diagnose einer Akromialgelenkentzündung begründet sich nach unseren mitgeteilten Erfahrungen auf folgenden Punkten:

I. örtliche Veränderungen: Druckschmerz, Gelenkerguß, Veränderung der Verankerungsfestigkeit des akromialen Schlüsselbeinendes im Gelenk (im Sinne der Lockerung oder abnormen Fixierung), Callus oder Randwucherung, Verdickung des subkutanen Schleimbeutels;

2. Störungen des Schultermechanismus: vor allem Hemmung der Achselverschiebungen nach oben, vorn oder hinten, verbunden mit Schmerz und Krepitation, wobei

a) der Schmerz auf die Schulterhöhe oder dahinter lokalisiert wird, ev. von da nach der Außenseite des Arms bis zum Deltamuskelansatz ausstrahlt,

b) die Krepitation streng auf das Gelenk beschränkt, stärker ist als die auf der gesunden Seite und mit den Schmerzen zusammenfällt ;

3. Nachweis von Form- und Strukturveränderungen mittels Röntgenstrahlen;

4. Beseitigung der subjektiven und objektiven Störungen durch Novokaininjektion ins Gelenk, ev. auch in den subdeltoiden Raum.

Die Diagnostik der Akromialgelenkerkrankungen bedarf sicher noch in mancher Beziehung des Ausbaues. Ich glaube aber, $\mathrm{da} ß$ es der Mühe verlohnt, da wir nur mit Hilfe weitgehender Differenzierung im Verständnis der stumpfen Schulterverletzungen weiterkommen und da ferner eine therapeutische Beeinflussung, die lokal am Akromialgelenk angreift, recht befriedigende Erfolge zeitigen kann.

Selbstverständlich wird es erforderlich sein, unsere klinischen und röntgenologischen Befunde durch pathologisch-anatomische Untersuchungen zu stützen. Die bei unseren Resektionen gefundenen Veränderungen können deswegen noch nicht als genügend angesehen werden, weil normale Vergleichs- 
befunde fehlen. Immerhin bedeutet der histologische Befund in Fall 2, den der Prosektor des pathologischen Instituts der Universität, Herr Professor Dr. Versé, zu kontrollieren die Freundlichkeit hatte, eine Bestätigung dafür, da $B$ wir uns auf richtigem Wege befunden haben, da ausgesprochen entzündliche Veränderungen im Anschluß an einen traumatischen Defekt der Knorpeloberfläche des Schlüsselbeinendes festgestellt werden konnten.

Für die Behandlung der frischen Akromialgelenkerkrankungen möchte ich in erster Linie die ev. wiederholte In jektion eines Anästhetikums vorschlagen, und zugleich eine einige Tage dauernde Ruhestellung, falls es sich um eine reine Akromialerkrankung handelt. Bei den chronischen Fällen treten die bekannten Mittel: Heißluft, Massage, Thermopenetration und Übungen in ihr Recht, freilich hörten wir nur in Fall 6 diese - N. B. nach der Novokaininjektion - wirklich loben, wo es sich um eine relativ frische (rezidivierende) Affektion handelte. Bei schwereren chronischen Veränderungen des Gelenks wird nicht viel erreicht, ebensowenig wie an anderen Gelenken, und doch erlebt man bei arbeitswilligen Personen Überraschungen, wie in Fall I3 (allerdings dem einzigen Fall ohne Trauma), wo die Beschwerden nach einem Jahr trotz hochgradiger Veränderungen verschwunden waren. Hier hatte bezeichnenderweise die Schonung des Gelenks während der interkurrenten Erkrankung (Leistenbruchoperation) überhaupt erst erheblichere Schmerzen ausgelöst. Ähnliches erlebt man ja auch sonst bei Arthritis deformans.

Meist verschwinden die Beschwerden aber nicht, und können so lästig sein, daß sie die Arbeitsfähigkeit stark beeinträchtigen. In solchen Fällen können wir auf Grund unserer drei Erfahrungen, denen sich jetzt ein neuer Fall anreihen wird, die Resektion des Gelenks empfehlen, die aber erst nach gewissenhaften Versuchen mit anderen Mitteln und nach absoluter Sicherstellung der Diagnose vorgenommen werden darf.

Die so operierten drei Kranken (2, 9, I2) waren mit den Resultaten der Operation zufrieden und konnten ohne wesentliche Störung ihrer Arbeit nachgehen. 
Die Resektion des Akromialgelenks ist eine sehr einfache, unter Lokalanästhesie ausführbare Operation. W. Müller beschreibt sie übrigens genauer in dem neuen Handbuch von Bier, Braun und $\mathrm{Kümmell}$. Wir bevorzugen einen Schnitt, der nicht das Gelenk berührt. Die Implantation eines Fettlappens ist deswegen zweckmäßig, weil sich der Gelenkspalt sonst durch Apposition zu sehr verkleinern und die alten Beschwerden erzeugen könnte, die Mobilisierung des Gelenks, wie eine mäßige Diastase der Gelenkflächen, daher als eine wünschenswerte Folge der Operation anzusehen ist. Interessant ist, daß in Fall 9 an der Stelle des Fettlappens später eine meniscusartige Einlagerung zu fühlen war, wie sie auch Röpke auf dem vorjährigen Kongreß beschrieb. Nach den bisherigen Fällen erschien auch eine leichte Subluxation des Clavicularendes nicht besonders störend (Fall 9). Immerhin haben wir bei einem neueren, noch nicht mitgeteilten Falle die beiden Resektionsenden nach Fettimplantation mit einem Stück Fascia lata dorsal gedeckt und so das Ligamentum acromioclaviculare wieder hergestellt.

Das Zustandekommen einer eigentlichen $\mathrm{Luxation}$ ist auch ohne diese Fixation nicht zu fürchten bekanntlich aus dem Grunde, weil das akromiale Schlüsselbeinende durch die festen Ligg. coracoclavicularia (Trapezium und Conoideum) fixiert bleibt.

Wir halten auf jeden Fall die Mobilisierung des Akromialgelenks für zweckmäßiger als eine Ankylosierung, wie sie Bähr in seinen Diastasefällen vorschlägt und wie sie von verschiedenen Autoren für die irreponible Luxation der Clavicula am akromialen Ende teils mit Hilfe von Nägeln, teils von Drahtnaht hergestellt worden ist (Cooper, Wirz, Paci, Krecke, Meyer).

Unsere Resektionsfälle zeigen, daß die Lockerung des Gelenks nicht schädlich wirkt, während bei der Vielseitigkeit der Aufgaben des Akromialgelenks der Ausfall des Gelenks durch Versteifung stets sich sehr fühlbar machen muß. Interessant ist die Beobachtung Alegianis, daß in einem Falle von Schultergelenkankylose eine besonders große Beweglichkeit des Akromialgelenks vorlag, weswegen A legiani für eine ,Arthrolys is acromioclavicularis" in Fällen von Schulterankylose plädiert. Auch Fick erwähnt, daß er die freieste Beweglichkeit im 
Akromialgelenk bei einem Falle unreponierter Schulterluxation gefunden habe.

An der Leiche kann man sich von der überraschenden Lockerkeit der akromialen Gelenkverbindung überzeugen, die allerdings durch die straffe Bandverbindung zwischen Clavicula und Processus coracoideus wesentlich beschränkt wird.

SchluBsätze.

Die Bewegungen der menschlichen Schulter finden an vier Stellen statt:

I. in der Articulatio humeroscapularis,

2. im Spatium subdeltoideum,

3. zwischen dem Schultergürtel und dem Rumpfe,

4. im Schultergürtel selbst.

Alle vier Stellen können selbständig und kombiniert von stumpfen Verletzungen der Schulter getroffen werden.

Das Spatium subdeltoideum erkrankt vor allem in Form diffuser Obliteration, wobei seine Gleitfähigkeit auch durch die Vernichtung der Bursa subacromialis und subdeltoidea, nicht aber durch ihre entzündliche Erkrankung aufgehoben wird.

Die Bursitis subacromialis und subdeltoidea ist ein besonders in ihren chronischen Stadien noch nicht sicher gestelltes Krankheitsbild. Das Vorkommen der Bursitis calcarea dürfte zweifellos sein.

Die Beweglichkeit des Schultergürtels in sich selber, d. h. im Akromioclaviculargelenk spielt eine von klinischer Seite nicht genügend gewürdigte Rolle. Das Gelenk nimmt an allen Bewegungen des Schultergürtels und des Armes teil, indem es sich um eine typische vertikale und sagittale Achse dreht. Vorzüglich gefördert werden durch dieses Gelenk die Bewegungen des Armes nach vorn, etwas weniger die nach der Seite, während die nach hinten und die rotatorischen mehr im Sinne von Hebelwirkungen angreifen. Wichtig sind die typischen Bewegungen des Akromialgelenks, die mit den selbständigen Bewegungen des Schultergürtels einhergehen.

Das Akromialgelenk erkrankt häufig im Anschluß an stumpfe Schulterverletzungen, die entweder in Form direkter 
Stauchung und Quetschung angreifen oder indirekt vom Ellenbogen oder der Hand her übertragen werden.

Diese Traumen haben entzündlich-degenerative Erkrankungen des Gelenks zur Folge, die in Form der akuten oder chronischen Arthritis acromialis sich klinisch und röntgenologisch bemerkbar machen.

Die Arthritis acromialis tritt entweder ganz selbständig auf infolge von Kontusion oder Distorsion oder mit Fraktur am akromialen Ende der Clavicula.

Die Erkrankung des Gelenks kann für sich bestehen, wie auch mit anderen traumatischen Affektionen des Schultergürtels und Schultergelenks kombiniert sein, von denen sie sich aber diagnostisch einigermaßen sicher abgrenzen läßt, insbesondere auch von den Affektionen des subdeltoiden Raumes.

Die Diagnose beruht vor allem auf den Störungen der normalen Funktionen des Gelenks, von denen als besonders wichtig und charakteristisch die die Schultergürtelbewegungen begleitenden anzusehen sind. Die Diagnose wird oft erleichtert durch örtliche, klinisch nachweisbare Veränderungen am Akromialgelenk, sowie durch eigenartige subjektive Beschwerden.

Das Röntgenverfahren, das eine eigene Technik der sagittalen und axialen Schulteraufnahmen erfordert, soll in jedem Falle angewandt werden und stets auch die gesunde Seite wie die Schultergelenke umfassen.

Die Arthritis acromialis ist eine praktisch wichtige Affektion, da sie mit lebhaften Schmerzen und Bewegungsstörungen einhergehen und langwierige Arbeitsunfähigkeit verursachen kann.

Die akute Form ist mit $R$ uhe und Novokaininjektionen zu behandeln und offenbar gut zu beeinflussen. Die Novokaineinspritzungen ins Gelenk und unter dasselbe in das Spatium subdeltoideum sind auch als ein bequemes und unschädliches diagnostisches Hilfsmittel zu empfehlen.

Die chronische Arthritis verhält sich den üblichen Mitteln gegenüber in vielen Fällen refraktär. Sind diese genügend lange Zeit hindurch vergeblich angewandt und die Diagnose gesichert, so kann die Resektion des Akromial- 
Die Arthritis acromio-clavicularis als wichtiges Glied in der Pathologie usw. 651

gelenks unter Implantation eines Fettlappens sehr erfreuliche Erfolge erzielen.

Die Operation hat eine Mobilisierung, nicht die Ankylose des Gelenks anzustreben.

\section{Literaturverzeichnis.}

I. Bähr, Die traumatische Diastase des Akromioclaviculargelenks. Zentralbl. f. Chir. 1895, Jahrg. 22, H. 44, S. 993-995.

2. Beltz, Demonstration eines Falles von Bursitis subacrom. Rhein.-Westf. Gesellschaft $\mathrm{f}$. innere Medizin u. Nervenhejlkunde. 22. Versammlung am 20. XI. igio.

3. Bergemann u. Stieda, Über die mit Kalkeinlagerung einhergehende Entzündung der Schultergelenksschleimbeutel. Münchn. med. Wochenschr. 1908. Jahrg. 55, Nr. 52, S. 2697-2702.

4. Blencke, Bursitis subacromialis (Demonstration). Medizinische Ge. sellschaft zu Magdeburg. Sitzung vom 5. XII. I9IO. Münchn. med. Wochenschr. I9I I, Jahrg. 58, S. 767.

5. Braune u. Fischer, Uber den Anteil, den die einzelnen Gelenke des Schultergürtels an der Beweglichkeit des menschlichen Humerus haben. Abhandlungen d. Kgl. sächs. Akademie d. Wissenschaften zu Leipzig, mathem.-physik. Klasse I888, Bd. 14 .

6. Calatajud et Estopina, A propos d'un cas de synovite calcifiante sous deltoidienne diagnostiqué par la radiographie. Ann. d'életrobiol. et de radiol. 1913, I6, S. 117-124.

7. Defranceschi, Über die supraakromiale Luxation der Clavicula. Berl. klin. Wochenschr. I892, Bd. 29, S. 575-580.

8. Duchenne, Biologie des Mouvements. Paris 1867.

9. Duplay, De la periarthrite scapulorhumérale et des raideurs de l'épaule, qui en sont la conséquence. Arch. gén. de Médicine 1872, Nr. II.

ı0. - De la periarthrite scapulo-humérale. La semaine medic. I896, Nr. 25.

II. F ick. Handbuch der Anatomie und Mechanik der Gelenke. Jena, Gustav Fischer. rgo4-igr.

12. Flint, Acut Traumatic subdeltoid Bursitis. A new and simple treatment. Journ. of the amer. med. assoc. 1913, Bd. 6o, Nr. I6, S. 1224-I225.

13. Ga upp, Über die Bewegungen des menschlichen Schultergürtels und die Ätiologie der ,Narkosenlähmungen". Zentralbl. f. Chir. I894, Nr. 34.

14. Grashey, Atlas typischer Röntgenbilder vom normalen Menschen. Lehmann, München 1912.

15. Gruber, Uber die Arten der Akromialknochen und akzidentellen Akromialgelenke. Arch. f. Anat. u. Physiol. u. wissenschaftl. Medizin. Leipzig, Jahrg. 1863, S. $373-387$. 
I6. $\mathrm{H}$ a e $\mathrm{nisch}$, Über die Periarthritis humeroscapularis mit Kalkeinlagerung im Röntgenbilde. (Bursitis subdeltoidea und subacromialis; Duplaysche Krankheit.) Fortschritte auf dem Gebiet der Röntgenstrahlen I9Io, Bd. XV, H. 5, S. 293-30o.

17. - Arthritis deformans des Schultergelenks. Diskussionsbemerkungen. Biol. Abt. d. ärztl. Vereins, Hamburg. Ref. Münchn. med. Wochenschr. I9II, S. 1266-1267, Nr. 23.

I8. Heineke, Die Anatomie und Pathologie der Schleimbeutel und Sehnenscheiden. Erlangen 1868.

19. He n ke, Handbuch der Anatomie und Mechanik der Gelenke. Leipzig I863.

20. H u eter, Klinik der Gelenkkrankheiten mit Einschluß der Orthopädie. III. Teil. 2. Aufl. Leipzig I878, F. C. W. Vogel.

2I. Jarjavay, Sur la luxation du tendon de la longue portion du muscle biceps huméral. Gazette hebdomadaire i 867.2 série, p. 325.

22. I $\mathrm{mm}$ elma $\mathrm{n}$, Über die Periarthritis humeroscapularis. Berliner medizinische Gesellschaft, 22, II. Ref. Münchn. med. Wochenschr. I9II, S. 982 .

23. Krecke, Zur Naht der Luxatio claviculac supraacromialis. Münchn. med. Wochenschr. I897, Jahrg. 44, Nr. 50, S. I44I-I 443.

24. Küster, Über Bursitis subacromialis (Periarthritis humero-scapularis). Arch. f. klin. Chir. I902, Bd. 65, S. Ior3-Io2 I (3I. KongreB).

25. Lilienfeld, Über das Os acromiale secundarium und seine Beziehungen zu den Affektionen der Schultergegend. Fortschritte auf dem Gebiet der Röntgenstrahlen I9I3, Bd. 2I, H. 2.

26. L otsy, Radiographischer Nachweis einer Bursitis subdeltoidea. Fortschritte auf dem Gebiete der Röntgenstrahlen I9ro/I9ı I, Bd. I6, S. I58 bis 159 .

27. Lud ewig, Akromialknochen auf der cinen, durch Pseudarthrose geheilte Fraktur des äußeren Schlüsselbeinendes auf der anderen Seite. Arch. f. klin. Chir. 1865, Bd. 7, S. I67-173.

28. M e yer, H., Statik und Mechanik des menschlichen Knochengerüstes. Leipzig 1873, S. I24.

29. M e yer, W. A., Zur Behandlung der Clavicularluxation. Deutsche Zeitschr. f. Chir. I9I3, Bd. I I9, S. 497.

3o. $\mathrm{M}$ iramond de $\mathrm{L}$ a roquet $\mathrm{t} \mathrm{e}$, Mesure radiographique des mouvements de l'épaule. Arch. d'électro-méd. I9I3, Jahrg. 21, Nr. 360, S. 529 bis 536.

3r. Mollier, Über die Statik und Mechanik des menschlichen Schultergürtels unter normalen und pathologischen Verhältnissen. Festschrift zum 7o. Geburtstag von $\mathrm{Karl}$ v. Kupffer. Jena I899, Gustav Fischer.

32. Müller, W., Abschnitt XXII der B i er-, B raun-, K ümmelschen chirurgischen Operationslehre: Operationen an der oberen Extremität. Leipzig I9I3, Ambr. Barth. 
Die Arthritis acromio-clavicularis als wichtiges Glied in der Pathologie usw. 653

33. Payr, Erkrankungen der Knochen und Gelenke in Wullstein-Wilms Lehrbuch der Chirurgie I909, II., 2.

34. - Über die operative Mobilisierung ankylosierter Gelenke. Münchn. med. Wochenschr. I910, Jahrg. 57, Nr. 37, S. 192 I-I927.

35. Preiser, Besprechung einiger Fälle der Röntgenschatten gebenden Bursitis subacromialis auf der 6. Tagung zu Bremen am I2. XI. IgIo der Vereinigung nordwestdeutscher Chirurgen. Ref. Zentralbl. f. Chir. I9I I, Jahrg. 38, Nr. 4, S. I 16.

36. - Statische Gelenkerkrankungen. Stuttgart I9I I, F. Encke.

37. Röpke, „Über die Verwendung freitransplantierten Fettes in der Gelenkchirurgie“. 42. Kongreß der Deutschen Gesellschaft für Chirurgie I9I3.

38. Schlesing er, Über periartikuläre Erkrankungen der Schultergegend. (Periarthritis humero-scapularis.) Berl. klin. Wochenschr. 1908, Nr. 5, S. $249-252$.

39. Sti eda, Zur Pathologie der Schultergelenksschleimbeutel. Arch. f. klin. Chir. 1908, Nr. 85, S. 910-924.

40. Thiem, Handbuch der Unfallkrankheiten. Artikel von Schmidt (Cottbus) über Verletzungen und Erkrankungen der Knochen und Gclenke in Band II. Stuttgart I9Io.

41. Vogt, Die chirurgischen Erkrankungen der oberen Extremitäten. Deutsche Chirurgie 188I (Billroth und Luecke), Lieferung 64.

42. Wr ed e, Über Kalkablagerungen in der Umgebung des Schultergelenks und ihre Beziehungen zur Periarthritis humero-scapularis. Arch. f. klin. Chir. 1912, Bd. 99, S. 259, 272.

43. Winslow, Exposition anatomique et la structure du corps humain. Amsterdam $\mathbf{1 7 4 3 .}$

44. Z es a s, Die Periarthritis humero-scapularis (D uplay sche Krankheit). Zeitschr. f. orthopäd. Chir. I909, Bd. 24, S. 175-186. 